\title{
Synthesis of Fatty acid-based polyesters and their blends with Poly(L-Lactide) as a way to tailor PLLA
}

\section{toughness}

Thomas Lebarbé, ${ }^{1,24}$ Etienne Grau, ${ }^{1,2}$ Benoit Gadenne, ${ }^{3}$ Carine Alfos ${ }^{3}$ and Henri Cramail ${ }^{* 1,2}$

${ }^{1}$ Université de Bordeaux, Laboratoire de Chimie des Polymères Organiques, ENSCBP, 16 Avenue Pey-Berland, Pessac Cedex, F 33607 France.

${ }^{2}$ CNRS, Laboratoire de Chimie des Polymères Organiques, F 33607 Pessac Cedex, France.

${ }^{3}$ ITERG, 11 rue Gaspard Monge, Parc Industriel, Pessac Cedex, F 33600, France.

${ }^{4}$ French Environment and Energy Management Agency, 20 avenue du Grench E-BP 90406, Angers Cedex 01, F 49004, France

*cramail@enscbp.fr

KEYWORDS: Sustainable polymers, Poly(L-lactide), polyesters, fatty acids, plant oils, toughening, impact resistance, crystallization. 


\section{ABSTRACT}

Polylactide (PLA) is one of the most mature bio-based and bio-compostable plastics currently in the market. Despite its mechanical properties comparable to the ones of some mainstream petroleum based thermoplastics (PS for instance), PLA inherent brittleness and heat sensitivity are issues for its full industrial development. In this study, we investigated melt-blending of PLLA (poly-L-lactide) with fatty acid-based flexible polyesters, as an efficient way to tailor PLLA toughness. To that aim, a set of aliphatic polyesters has been developed by taking benefit of the large range of bio-based building blocks that can be obtained from plant oils. Meltblending of the so-formed polyesters with PLLA resulted in improved properties which can be finely tailored by varying the structure and the properties of the plant-based polyester additives.

\section{INTRODUCTION}

Bio-based polymers have retained considerable attention from academia and industry in recent years due to certain oil depletion and environmental issues. ${ }^{1-4}$ Among them, polylactide (PLA) is one of the most mature biopolyesters with a global capacity of over 180000 metric tons per year ( $16 \%$ of the bio-based plastics global production capacity in 2011$).{ }^{5}$ PLLA (poly-L-lactide) is synthesized by ring-opening polymerization of L-lactide, a cyclic dimer of lactic acid that can be derived from starch crops fermentation. ${ }^{6-8}$ The promising mechanical properties of PLLA such as its high stiffness are however counterbalanced by its inherent brittleness as evidenced by its low value of notched IZOD impact strength $\left(2.45 \mathrm{~kJ} \cdot \mathrm{m}^{-2}\right) .{ }^{9-12}$ Thus various solutions were developed to limit the brittleness of PLLA such as plasticization, copolymerization and blending. ${ }^{13-16}$ Rubber-toughening by melt-blending PLLA with a low Tg polymer (usually called rubber) is 
often described as an effective solution to limit PLLA's brittleness. Indeed, this versatile approach allows the tuning of PLLA mechanical properties depending on the rubber used. ${ }^{15}$ To be effective, the rubber must address some important requirements such as (i) a non-miscibility but a good interfacial adhesion to PLLA in order to obtain a fine distribution of the rubbery particles in the matrix (usually $0.1-1.0 \mu \mathrm{m}$ ), (ii) a glass transition temperature at least $20^{\circ} \mathrm{C}$ lower than the test/use temperature, (iii) no crystallinity or a very low crystallinity and, (iv) a thermal stability at the PLLA processing temperatures. ${ }^{17}$

Use of non-biodegradable petroleum-based polymers such as olefins, ${ }^{18-21}$ acrylics ${ }^{22,23}$ and styrenics $^{24,25}$ for the toughening of PLLA was already investigated. In such systems, reactive functions on the polymers backbone or third components were most of the time added to enhance interfacial adhesion between PLLA and the dispersed phase. ${ }^{26-30}$ However, such polymeric additives do not constitute long-term and suitable solutions as they modify the compostable feature of the final PLA material thus suppressing one of the main advantages of PLLA.

For this reason, a second generation of PLLA impact modifiers that consists of biodegradable and bio-based additives, was considered. Various rubbers such as poly( $\varepsilon$-caprolactone), ${ }^{31-35}$ poly(butylene succinate) $)^{36,37}$ and their copolyesters, poly(butylene adipate-co-terephtalate), ${ }^{38,39}$ polyhydroxyalkanoates ${ }^{40-42}$ were melt blended with PLLA resulting in improved material's ductility.

Limited examples concerning the toughening of PLLA by amorphous or low crystalline second generation impact modifiers were described. Zhang and coll. have synthesized a bio-polyester by condensing sebacic, itaconic and succinic acids with propanediol and butanediol mixture. ${ }^{43}$ The resulting polyester showed a slight crystalline behaviour, however the low melting point (below room temperature) was in agreement with the requirements for PLLA toughening. Melt blending 
this polyester with PLLA resulted in a significant improvement of the toughness of PLLA (notched IZOD impact strength as high as $13.4 \mathrm{~kJ} . \mathrm{m}^{-2}$ for $22.6 \mathrm{vol} \%$ of additive in comparison to $2.4 \mathrm{~kJ} . \mathrm{m}^{-2}$ for neat PLLA). ${ }^{44}$ In another study, Dubois and coll. synthesized random copolyesters based on $\varepsilon$-caprolactone and $\delta$-valerolactone. ${ }^{45}$ For optimal compositions, the copolymers showed a low melting point at around $15^{\circ} \mathrm{C}$. Improved impact strength was noticed when these copolyesters were melt-blended with PLLA. Similarly, the same authors used $\varepsilon$-caprolactone and D,L-lactide to synthesize amorphous random copolyesters impact modifiers for PLLA. ${ }^{35}$ The presence of lactide units in the copolyester structure allowed an improved miscibility with the PLLA matrix. Moreover, blends with PLLA induced enhanced impact strength of the final material (11.4 kJ.m ${ }^{-2}$ for $28 \mathrm{wt} \%$ of additives) in comparison to $2.7 \mathrm{~kJ} . \mathrm{m}^{-2}$ for neat PLLA.

With the objective to investigate PLLA toughening by blending with bio-based aliphatic polyesters, we selected plant oils as starting renewable resources. Vegetable oils, which are annually renewable, are one of the most important sustainable raw materials for the chemical industry. ${ }^{46-49}$ From commodity vegetable oils, fatty acids are available in such purity that they can be used as polymer precursors by chemical conversions. ${ }^{48,49}$ For the development of new bio-based low Tg polymers (rubbers), we selected commercially available sebacic acid (SA) and hydrogenated dimer of C18 fatty acids (DFA) as hard and soft precursors respectively. These diacid monomers (used in various amounts) were copolymerized with 1,10-decanediol (obtained by reduction of SA) resulting in a series of aliphatic polyesters. The influence of the structure of these polyesters on the properties of the PLLA/polyester blends is evaluated. In particular, the morphology, thermal behaviors, rheological properties and mechanical properties of the blends are investigated. 


\section{Synthesis and characterization of the polyester rubbers}

A set of polyesters was synthesized by varying the SA/DFA ratio in order to tune the crystallinity of the polyester and evaluate its influence on the blends with PLLA. The polyesters were synthesized by bulk polycondensation using titanium isopropoxide as a catalyst with various feed ratios between the linear SA and the branched DFA diacids (Fig 1).

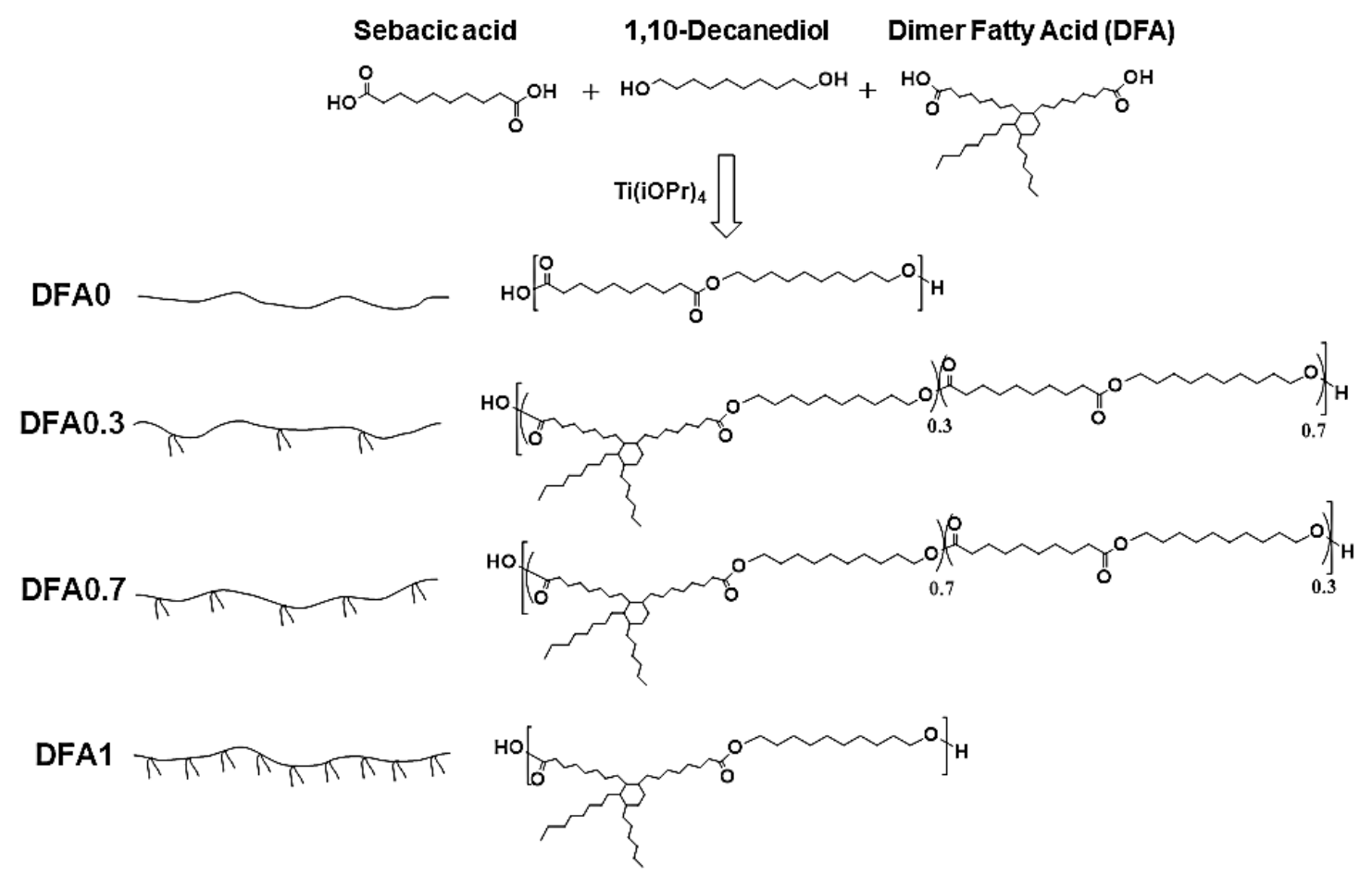

Figure 1. Synthetic strategy to polyester rubbers

After completion of the polymerization, the polyesters were analyzed by ${ }^{1} \mathrm{H}-\mathrm{NMR}$ (see Fig 2). The formation of ester linkages can be confirmed by the characteristic peaks at 4.04 and 2.28 ppm corresponding to $\mathrm{CH}_{2} \mathrm{O}$ and to $\mathrm{CH}_{2} \mathrm{COO}$ respectively.

The absence of characteristic peaks of hydroxyl and carboxylic acid functions demonstrates the high conversion of the monomers and the formation of high molecular weight polymers (see Table 1). The multiplet figuring at $0.88 \mathrm{pm}$ is assigned to the methyl group of the dangling alkyl chains thus confirming the incorporation of DFA units in the polyester structure. The ratio 
between SA and DFA units in the structure of the polyesters was calculated from the ratio of the $0.88 \mathrm{ppm}$ to $2.28 \mathrm{ppm}$ peak normalized integrals. The chemical composition of the polyesters was slightly different from the feed ratio of the monomers (Table 1). This can be explained by a few distillation of SA and/or 1,10-decandiol during the polymerization. Nevertheless the impact on $-\mathrm{COOH} /-\mathrm{OH}$ remain appears to be minor since high molecular weights were found in the range 36-64 kg. mol ${ }^{-1}$ with expected dispersities in the range 1.8-2.1 (Table 1).

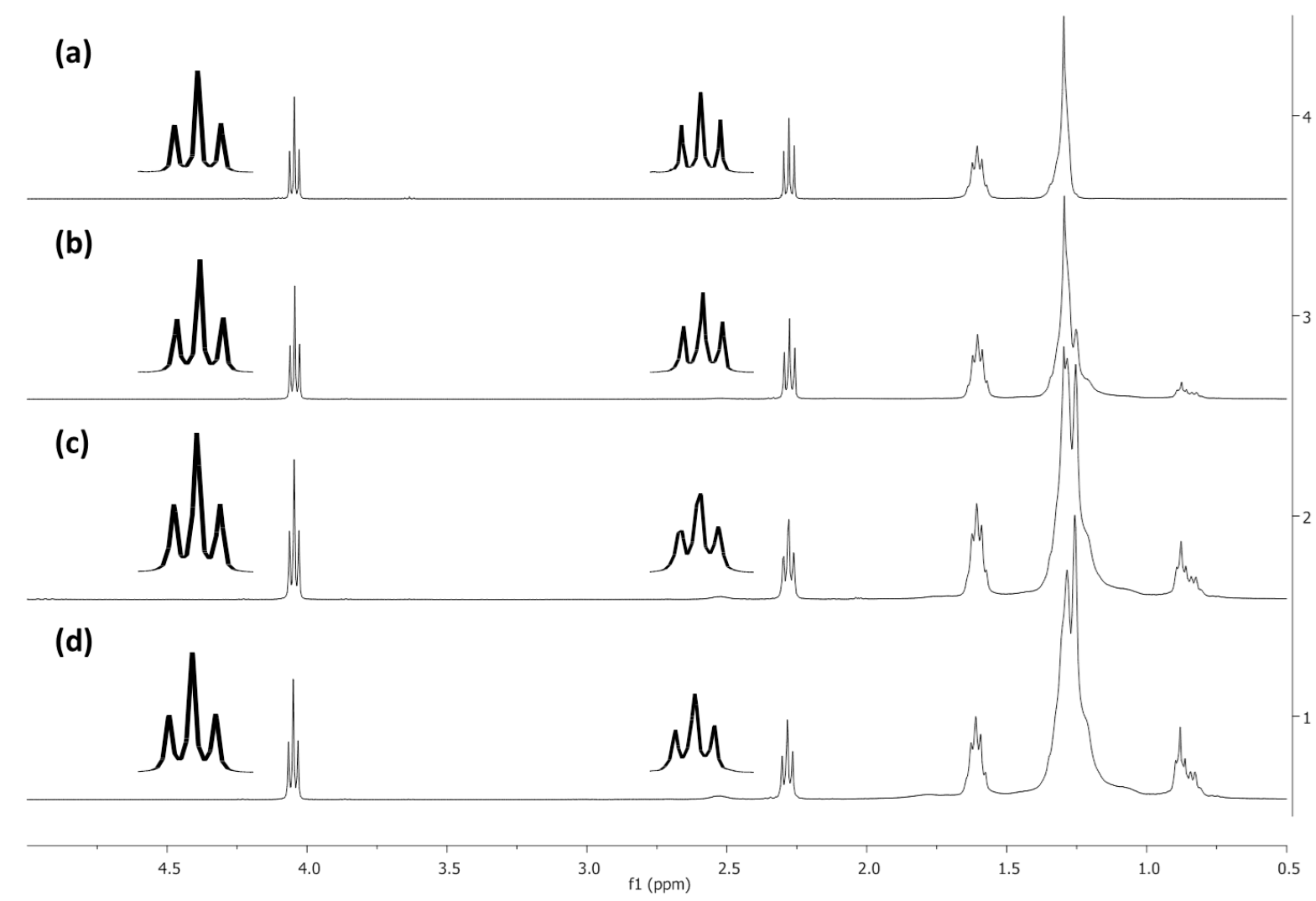

Figure 2. ${ }^{1} \mathrm{H}-\mathrm{NMR}$ stacked spectra of (a) DFA0 (b) DFA0.3 (c) DFA0.7 (d) DFA1 in $\mathrm{CDCl}_{3}$.

TGA experiments (see SI Fig S1 and Table S1) were carried out to evaluate the degradation temperature of the polyesters. The synthesized polyesters present higher thermal stabilities than neat PLLA thus allowing their use as impact modifier. Indeed the first weight loss (temperature corresponding to $5 \%$ weight loss) is observed near $390^{\circ} \mathrm{C}$ and $335^{\circ} \mathrm{C}$ for polyester rubbers and 
PLLA respectively. Only DFA0 showed a lower degradation temperature than the other polyesters $\left(338^{\circ} \mathrm{C}\right.$ for $5 \%$ weight loss); DFA inducing a better thermal stability in comparison to the purely linear polyester (DFA0).

Thermal analysis of the polyesters was then carried out by DSC to better evaluate the influence of the dangling alkyl chains density on the melting temperature and enthalpy of the polyesters. Tg was first measured to ensure that these polyesters can be used as toughening agents of PLLA. $\mathrm{Tg}$ values well below room temperature were measured (between $-50^{\circ} \mathrm{C}$ and $-46^{\circ} \mathrm{C}$ ) suggesting potential application for rubber toughening of PLA. Interestingly, the Tg value was only slightly impacted by the DFA amount showing that the dangling chains have limited influence on the macromolecular mobility of the polyesters. However significant influence of the DFA amount on the crystalline behavior of the polyesters was observed (Fig 3, and Table 1). Indeed, while the purely linear polyester (DFA0) showed a melting point at $78^{\circ} \mathrm{C}$, DFA1 presented a melting point

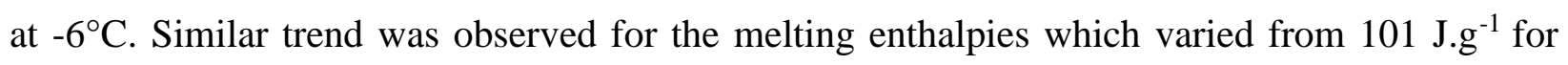

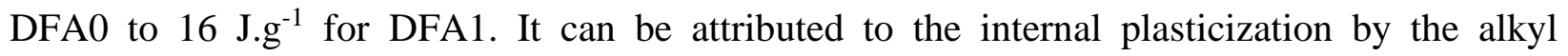
dangling chains that resulted in a lack of chain packing for high contents of DFA units.

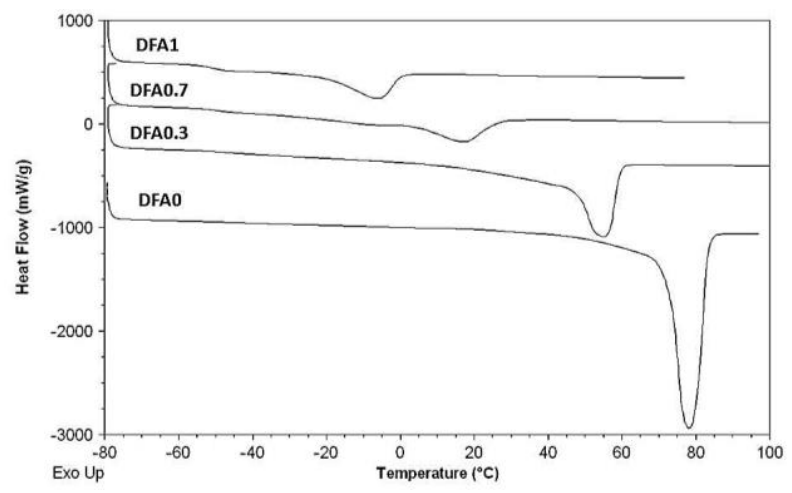

Figure 3. Heating curves of neat PLLA and of the polyesters $-10^{\circ} \mathrm{C} \cdot \mathrm{min}^{-1}$ from $-80^{\circ} \mathrm{C}$ to $120^{\circ} \mathrm{C}$. 
Table 1. General parameters of the polyesters formed by polycondensation of SA, DFA and decanediol and of neat PLLA.

\begin{tabular}{|c|c|c|c|c|c|c|c|c|c|c|}
\hline & $\begin{array}{c}\text { mol\% } \\
\text { DFA/total } \\
\text { diacid }^{\mathrm{a}} \\
\text { (feed) }\end{array}$ & $\begin{array}{c}\bar{M}_{n} \\
(\mathbf{k g . m o l} \\
\left.\mathbf{1}^{\mathbf{b}}\right)^{\mathbf{b}}\end{array}$ & $\boldsymbol{\oplus}^{\mathbf{b}}$ & $\begin{array}{c}\mathbf{T g} \\
\left({ }^{\circ} \mathbf{C}\right)^{\mathbf{c}}\end{array}$ & $\begin{array}{c}\text { Tc } \\
\left({ }^{\circ} \mathbf{C}\right)^{\mathrm{c}}\end{array}$ & $\begin{array}{c}\Delta \mathrm{HC} \\
(\mathrm{J.g} \\
1)^{\mathbf{c}}\end{array}$ & $\begin{array}{c}\mathbf{T m} \\
\left({ }^{\circ} \mathbf{C}\right)^{\mathrm{c}}\end{array}$ & 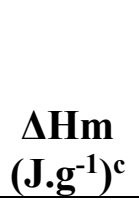 & $\begin{array}{c}\delta \\
\left(\text { cal.cm- }^{-}\right. \\
\left.3^{1 / 2}\right)^{1 / 2}\end{array}$ & $\mathbf{T}_{5} \%\left({ }^{\circ} \mathbf{C}\right)^{\mathrm{d}}$ \\
\hline DFA0 & $0(0)$ & 59 & 2.1 & -48.6 & 61.4 & 96.9 & 78.2 & 100.9 & 9.11 & 338 \\
\hline DFA0.3 & $0.40(0.3$ & 44 & 1.8 & -45.9 & 38.1 & 55.1 & 55. & 57.7 & 9.24 & 389 \\
\hline DFA0.7 & $0.78(0.7)$ & 64 & 2.0 & -49.0 & -11.5 & 25.9 & 17.7 & 22.4 & 9.31 & 399 \\
\hline DFA1 & $1(1)$ & 36 & 2.0 & -50.0 & -29.8 & 16.5 & -5.8 & 16.2 & 9.34 & 394 \\
\hline PLLA & - & 121 & 1.5 & 61 & 104.2 & 1.4 & 176.3 & 32.9 & 11.40 & 335 \\
\hline
\end{tabular}

(a) ${ }^{1} \mathrm{H}-\mathrm{NMR}$ (b) SEC in THF, PS calibration (c) DSC $-10^{\circ} \mathrm{C} \cdot \mathrm{min}^{-1} \delta$ was calculated using Hoftyzer-Van Krevelen method (d) TGA $-10^{\circ} \mathrm{C} \cdot \mathrm{min}^{-1}$ under $\mathrm{N}_{2}$

As mentioned above, to consider efficient energy release during impact, the additive compounded with PLLA has to be immiscible with the matrix and dispersed as fine particles (typically $0.1-1.0 \mu \mathrm{m}$ ). The Hoftyzer-Van Krevelen method was used in this study to calculate the solubility parameter of the polyesters so-formed. ${ }^{50}$ The calculated solubility parameters are given in Table 1 and suggest immiscibility of PLLA with all the polyesters as seen from the difference in the solubility parameter values of PLLA $\left(11.40\left(\mathrm{cal}_{\mathrm{cm}} \mathrm{cm}^{-3}\right)^{1 / 2}\right)$ and the ones of each polyester which is higher than $0.5\left(\mathrm{cal}_{\mathrm{cm}} \mathrm{cm}^{-3}\right)^{1 / 2} \cdot{ }^{44}$ It is noteworthy that the solubility parameter is increasing with an increase in DFA unit amount indicating enhanced interactions between the two phases when higher amounts of DFA were used.

To summarize, a set of aliphatic polyesters were synthesized by polycondensation. These polyesters showed very low $\mathrm{Tg}$ values (around $-50^{\circ} \mathrm{C}$ ) and a semi-crystalline behavior. The thermal stability of these polyesters was high enough to consider their use as additives in blends with PLLA. Finally, their potential immiscibility with PLLA should lead to typical two phase systems while in blends with PLLA, morphology which is mandatory for the efficient 
toughening of PLLA. All these preliminary characteristics prompted us to investigate their meltblending with PLLA as impact modifier.

\section{Processability and Morphology}

The so-formed polyesters (rubbers) were added in various amounts into a commercially available PLLA (Table 2) using a twin-screw micro-compounder in order to reach final contents of 10 and $20 \mathrm{wt} \%$ of rubber. Based on the conditions generally reported in the literature for such systems, the following conditions have been selected: melt-compounding for $5 \mathrm{~min}$ at $190^{\circ} \mathrm{C}$ and $50 \mathrm{rpm}$ followed by injection molding at $200^{\circ} \mathrm{C}$ in a mold kept at $50^{\circ} \mathrm{C}$ then the test bars stayed overnight at room temperature. It is worth mentioning that samples aging, which is particularly relevant in the case of PLLA, ${ }^{51-52}$ was not investigated in this study. Such processing conditions can afford a good compromise between good dispersion (related to shear) and limited material thermal degradation. Indeed, NMR spectra of the resulting blend in $\mathrm{CDCl}_{3}$ testified that no significant transesterification reaction took place between PLLA and the polyester since no new signal appears between 5.5 and 3.7 ppm (see Fig S3).

The thermal stability of the PLLA/Polyesters blends under non-oxidative conditions was first investigated by TGA in order to evaluate their processability. Figure 4 shows the TGA curves of neat PLLA and of the blends comprising $10 \mathrm{wt} \%$ of additive. 


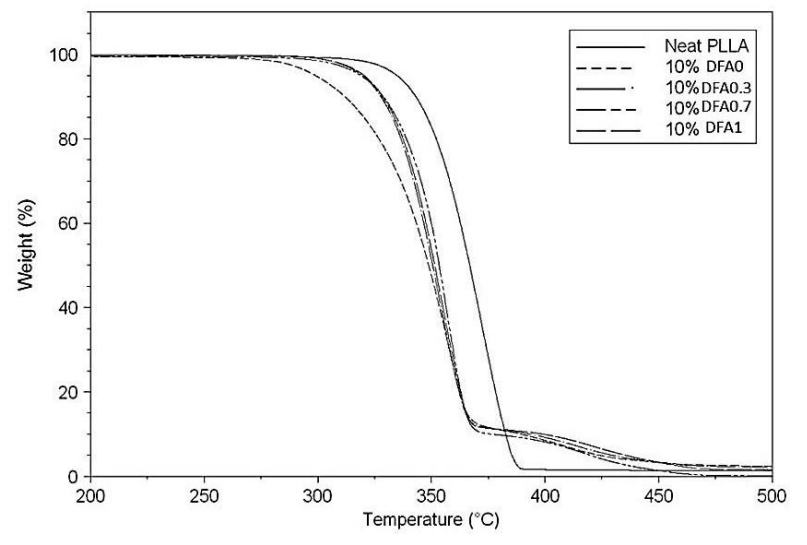

Figure 4. TGA curves of neat PLLA and of the blends comprising $10 \mathrm{wt} \%$ of additive recorded from $30^{\circ} \mathrm{C}$ to $500^{\circ} \mathrm{C}$ at $10^{\circ} \mathrm{C} \cdot \mathrm{min}^{-1}$ under a nitrogen atmosphere.

The decomposition parameters are given in Table 2. As observed in Figure 4, the thermal decomposition of the blends is occurring in two steps. A first weight loss is happening near $320^{\circ} \mathrm{C}$ and can be assigned to the degradation of the PLLA phase. A second weight loss occurring at higher temperatures (around $370^{\circ} \mathrm{C}$ ) is assigned to the degradation of the dispersed polyester phase. Interestingly, a slight decrease in initial degradation temperature was noticed when the polyester impact modifier was added into the PLLA matrix. Indeed, the temperature corresponding to $5 \mathrm{wt} \%$ loss shifted from $335^{\circ} \mathrm{C}$ for neat PLLA to around $320^{\circ} \mathrm{C}$ when $10 \mathrm{wt} \%$ of polyester was added. This decrease was more pronounced in the case of DFA0. Increasing amount of polyester in the blends $(20 \mathrm{wt} \%)$ did not resulted in further decrease in initial degradation temperature (Fig. S4). The two-step thermal decomposition allowed us the measurement of the weight composition of the blends (Table 2). Good agreement with the feed ratio was observed. 
Table 2. Thermal properties, weight compositions of the PLLA/polyester blends and mean diameter size of the rubber particles.

\begin{tabular}{ccccc} 
& & wt\% Rubber $^{\mathbf{a}}$ & $\mathbf{T}_{5 \%}\left({ }^{\circ} \mathbf{C}\right)^{\mathbf{a}}$ & $\overline{\boldsymbol{d}}(\boldsymbol{\mu m})^{\mathbf{b}}$ \\
\hline \multirow{4}{*}{ 10wt\% } & PLLA & - & 334.9 & - \\
& DFA0 & 12.0 & 298.9 & $0.34 \pm 0.13$ \\
& DFA0.3 & 11.9 & 319.6 & $0.54 \pm 0.27$ \\
& DFA0.7 & 10.8 & 319.1 & $0.48 \pm 0.16$ \\
& DFA1 & 11.7 & 320.3 & $0.69 \pm 0.32$ \\
\hline \multirow{3}{*}{ 20wt\% } & DFA0 & 22.7 & 292.2 & $0.92 \pm 0.46$ \\
& DFA0.3 & 21.8 & 319.7 & $0.99 \pm 0.61$ \\
& DFA0.7 & 20.7 & 315.0 & $0.64 \pm 0.36$ \\
& DFA1 & 22.0 & 314.2 & $1.35 \pm 0.63$ \\
\hline
\end{tabular}

(a) TGA, 20 to $700^{\circ} \mathrm{C}, 10^{\circ} \mathrm{C} / \mathrm{min}$ (b) calculated from SEM images using Image $\mathrm{J}$

A melt rheological study at $190^{\circ} \mathrm{C}$ (see Fig S5-6) confirmed that all the blends showed good melt processability with some variations of the elasticity and the viscosity of the blend depending on the rubber type as well as on the rubber content. Indeed lower viscosities were observed for the blends at high frequencies compared to PLLA.

To ensure the phase segregation, the different samples were cryo-fractured and the surfaces were observed using scanning electron microscopy (SEM). For all the samples, the morphologies were characterized by spheres and holes of rubber phase dispersed into the PLLA matrix. (see Fig. S9) Statistics from 200 randomly selected particles at each sample showed that the number-average particle diameter was in the range $0.34-1.35 \mu \mathrm{m}$ (Table 2). Thus, the fine dispersion obtained was in accordance with the requirement concerning optimal particle size, which was defined in the range $0.1-1.0 \mu \mathrm{m} .{ }^{17}$ As expected, the mean size diameter of the particles increased with an increase in the rubber amount in the blend. For instance, when DFA1 was used as a rubber, the number-average diameter of the particles increased from 0.69 to $1.35 \mu \mathrm{m}$ for the blends comprising $10 \mathrm{wt} \%$ and $20 \mathrm{wt} \%$ of rubber respectively. 


\section{Crystallization behavior}

Further investigations of the crystallization behavior of these blends were realized both during non-isothermal and isothermal crystallization experiments to study crystallization ability of PLLA when blended with polyester rubbers.

Non-isothermal crystallization was first investigated at a heating rate of $10^{\circ} \mathrm{C} \cdot \mathrm{min}^{-1}$ by cooling the samples from the melt to $-80^{\circ} \mathrm{C}$ and subsequently heating to $200^{\circ} \mathrm{C}$. DSC cooling and heating curves are shown in Figure 5. The crystallization peak of neat PLLA, when cooled from the melt, was rather small in comparison to the ones of PLLA phase in the blends. However, even in the case of the blends, PLLA phase did not have enough time to crystallize at $10^{\circ} \mathrm{C} \cdot \mathrm{min}^{-1}$. The glass transition of PLLA phase in the blends was readily identified and was similar to the one of neat PLLA suggesting that the matrix and the rubbers were phase-separated during cooling from the melt. By further cooling, crystallization of the dispersed phase was observed at various temperatures depending on the rubber used. By subsequent heating of the samples, the phase separation between the matrix and the rubbers was also confirmed by measuring the $\mathrm{Tg}$ of the PLLA phase during heating (Table 3). Indeed, similar Tg values were observed for neat PLLA and PLLA phase in the blends. Moreover the melting temperature of the rubber is not impacted. Dispersion of higher ratio of rubber into the matrix did not change the Tg values (Fig. 6). Further heating of the samples led to cold-crystallization of the PLLA phase as seen from the exothermic peaks figuring at around $100^{\circ} \mathrm{C}$. The cold-crystallization peak of neat PLLA was found at higher temperature $\left(129^{\circ} \mathrm{C}\right)$ and was much broader suggesting enhanced cold-crystallization ability of PLLA by dispersion of the rubbers. 

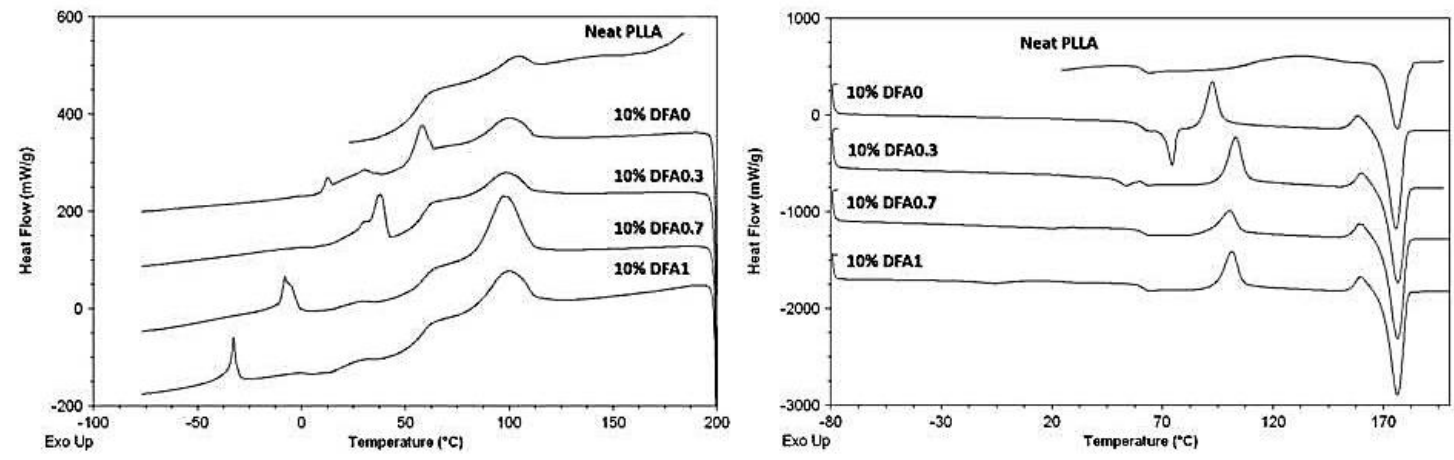

Figure 5. (a) Cooling curves and (b) heating curves of neat PLLA and the blends $-10^{\circ} \mathrm{C} \cdot \mathrm{min}^{-1}$ from $-80^{\circ} \mathrm{C}$ to $200^{\circ} \mathrm{C}$.

Interestingly, the melting point of PLLA phase remained unchanged $\left(\mathrm{Tm}\right.$ around $\left.176^{\circ} \mathrm{C}\right)$ when 10 and $20 \mathrm{wt} \%$ of rubber were added. It is however noteworthy that a small exothermic peak (around $162^{\circ} \mathrm{C}$ ) was observed just before the melting transition of PLLA. This peak is assigned to a solid-solid transition explained by the transformation of the meta-stable and disordered $\alpha^{\prime}$ crystals into more stable $\alpha$-crystals. ${ }^{53}$

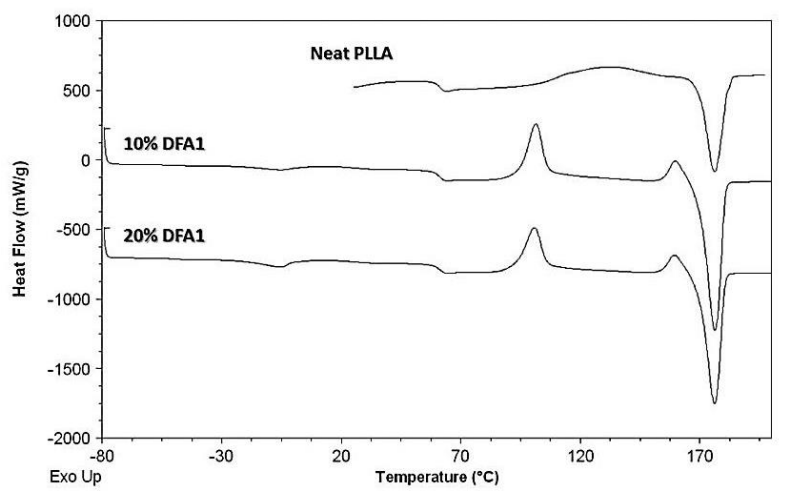

Figure 6. Heating curves of neat PLLA and the blends with DFA 1 as a rubber $-10^{\circ} \mathrm{C} \cdot \mathrm{min}^{-1}$ from $-80^{\circ} \mathrm{C}$ to $200^{\circ} \mathrm{C}$.

For all the blends, except with $10 \mathrm{wt} \%$ of DFA0.3, a significant increase in PLLA crystallinity was noticed. The most noticeable difference was measured with $20 \mathrm{wt} \%$ of DFA0.7. Indeed, for 
this sample, the crystallinity of PLLA phase reached $49 \%$ while neat PLLA showed a crystallinity value of $15 \%$. It was also observed that the crystallinity of the PLLA phase was enhanced by an increase of the rubber amount in the blend. In the case of the blends with DFA0.3 as a rubber, the crystallinity changed from $17 \%$ to $28 \%$ for a rubber amount of $10 \mathrm{wt} \%$ and $20 \mathrm{wt} \%$ respectively. From non-isothermal crystallization studies, we can then ensure that polyester rubbers also act as nucleating assisting agents.

Table 3. Thermal properties of neat PLLA and the blends. Measured by DSC at $10^{\circ}$ C. min $^{-1}$. Only PLLA related transitions are reported. \begin{tabular}{cccccc}
$\operatorname{Tg}\left({ }^{\circ} \mathrm{C}\right)$ & $\operatorname{Tcc}\left({ }^{\circ} \mathrm{C}\right)$ & $\Delta \mathrm{Hcc}\left(\mathrm{J} . \mathrm{g}^{-1}\right)$ & $\operatorname{Tm}\left({ }^{\circ} \mathrm{C}\right)$ & $\Delta \mathrm{Hm}\left(\mathrm{J.g}{ }^{-1}\right)$ & $\chi_{\mathrm{c}}(\%)$ \\
\hline
\end{tabular}

\begin{tabular}{rccccccc}
\hline & PLLA & 60.9 & 129.2 & 19.2 & 176.3 & 32.9 & 15 \\
\hline & DFA0 & 61.2 & 92.6 & 19.6 & 175.7 & 44.2 & 29 \\
$\mathbf{1 0 w t \%}$ & DFA0.3 & 60.7 & 103.1 & 24.6 & 176.5 & 38.7 & 17 \\
& DFA0.7 & 61.4 & 100.5 & 14.3 & 176.4 & 45.3 & 37 \\
& DFA1 & 61.7 & 101.4 & 19.2 & 176.4 & 45.4 & 31 \\
\hline \multirow{20w\%}{*}{$\mathbf{2 0 w t} \%$} & DFA0 & 61.3 & 92.8 & 16.8 & 175.3 & 40.1 & 31 \\
& DFA0.3 & 61.1 & 102.9 & 20.1 & 176.3 & 41.3 & 28 \\
& DFA0.7 & 63.8 & - & - & 177.0 & 36.8 & 49 \\
& DFA1 & 61.7 & 100.8 & 15.5 & 176.2 & 40.1 & 33 \\
\hline
\end{tabular}

Isothermal crystallization kinetics was also carried out by DSC to evaluate the behavior of the blends. The procedure was the following: the samples were first melted at $200^{\circ} \mathrm{C}$ for 3 minutes to erase the thermal history and were subsequently cooled rapidly at $110^{\circ} \mathrm{C}$ (this temperature corresponds to the maximum of PLLA crystallization determined by DSC) and kept at this temperature for 30 minutes. The isothermal crystallization data were then fitted to the Avrami equation (Table 4 and Fig. S7). 
Table 4. Isothermal crystallization parameters of neat PLLA and the blends $\left(110^{\circ} \mathrm{C}\right)$.

\begin{tabular}{ccccc} 
& & $\mathbf{n}$ & $\mathbf{k}\left(\mathbf{m i n}^{-\mathbf{n}}\right)$ & $\mathbf{t}_{\mathbf{1} / \mathbf{2}}(\mathbf{m i n})$ \\
\hline & PLLA & 1.80 & 0.027 & 6.12 \\
\hline DFA0 & 3.53 & 0.021 & 2.70 \\
$\mathbf{1 0 w t \%}$ & DFA0.3 & 3.73 & 0.014 & 2.85 \\
& DFA0.7 & 3.81 & 0.116 & 1.60 \\
& DFA1 & 4.20 & 0.015 & 2.48 \\
\hline \multirow{20wt\%}{*}{ DFA0 } & 3.92 & 0.011 & 2.86 \\
& DFA0.3 & 3.42 & 0.044 & 2.23 \\
& DFA0.7 & 3.80 & 0.384 & 1.17 \\
& DFA1 & 3.47 & 0.033 & 2.41 \\
\hline
\end{tabular}

The Avrami index $n$ was in the range 3.4-4.2 suggesting a three-dimensional crystal growth in accordance with what is generally described for such systems. ${ }^{54}$ It is noteworthy that the crystallization half-time was significantly decreased by the incorporation of $10 \mathrm{wt} \%$ of rubber. Indeed the value changed from $6.12 \mathrm{~min}$ for neat PLLA to $1.60 \mathrm{~min}$ for the blend containing 10 $\mathrm{wt} \%$ of DFA0.7. For the other rubbers, $\mathrm{t}_{1 / 2}$ values were in the range $2.48-2.85 \mathrm{~min}$. Similarly to the non-isothermal crystallization experiments, DFA0.7 seems to be the most effective rubber for the enhancement of the PLLA crystallization rate. Addition of more rubber into the PLLA matrix did not resulted in significant changes of the $t_{1 / 2}$ values. Interestingly, the most effective nucleating assisting agents (DFA0.7 and DFA1) were the rubbers that presented the best affinity (and lower melting points) with the PLLA matrix as seen from the calculated solubility parameters (Table 1). Thus, the higher crystallization rates could be linked to the increased mobility of PLLA chains at the matrix/rubber particle interface due to improved compatibility between the two phases inducing an enhancement in crystallization rate and/or in nucleation density. 


\section{Influence of the polyester structure on the toughening efficiency.}

Tensile tests (see Table 5 and Fig S8) were then performed on the blend to get a first evaluation of the material's toughness. This demonstrates promising results, indeed when $10 \mathrm{wt} \%$ of rubber was added, the failure changed from a brittle to a ductile behavior as seen from the distinct yielding which was followed with stable neck growth. An elongation at break value as high as $385 \%$ was obtained when $10 \mathrm{wt} \%$ of DFA0 was dispersed into the PLLA matrix. This constitutes a 100 fold increase compared to neat PLLA. Nevertheless, measurement of the notched impact strength (IS) represents a more accurate and useful method for the observation of fracture energy absorption during high loading. Thus notched IZOD IS tests results are presented in Table $\mathbf{5}$ and Figure 7.

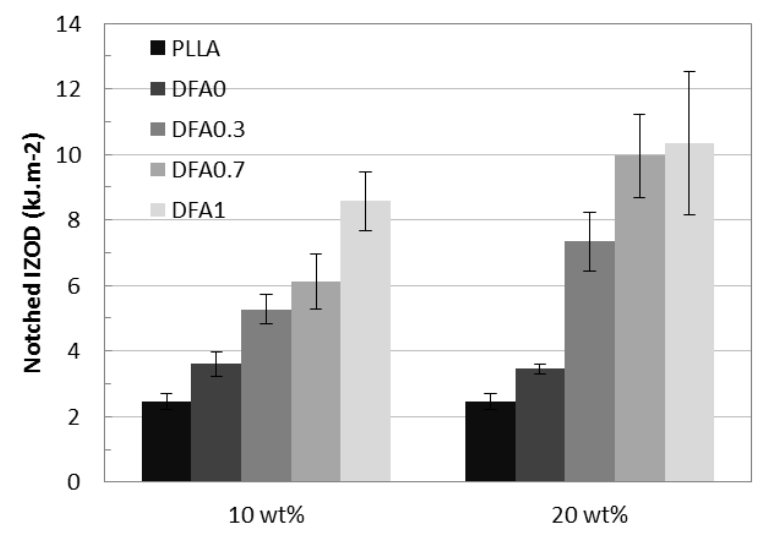

Figure 7. Notched IZOD impact strength of PLA-based materials containing 10 and 20wt\% of rubber.

An obvious correlation of the crystallinity degree of the rubbers with the impact strength of the blends can be established. Indeed, in the case of the highly crystalline DFA0 rubber $\left(\mathrm{Tm}\right.$ of $78^{\circ} \mathrm{C}$

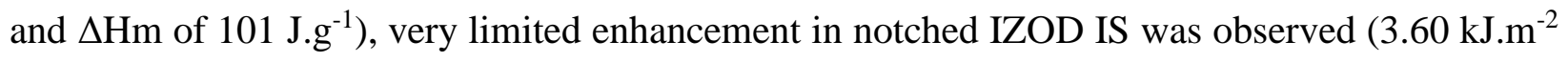
for $10 \mathrm{wt} \%$ of DFA0 compared to $2.45 \mathrm{~kJ} . \mathrm{m}^{-2}$ for neat PLLA). A decrease in crystallinity degree 
of the rubber resulted in a gradual enhancement of the IS value. For a rubber amount of $10 \mathrm{wt} \%$, the lowering of the melting point from $78^{\circ} \mathrm{C}$ to $-5.8^{\circ} \mathrm{C}$ and of the melting enthalpy from $101 \mathrm{~J} . \mathrm{g}^{-1}$ to $16.2{\mathrm{~J} . \mathrm{g}^{-1}}^{-1}$ respectively led to an increase in IZOD impact resistance from $3.60 \mathrm{~kJ} . \mathrm{m}^{-2}$ to 8.58 $\mathrm{kJ} . \mathrm{m}^{-2}$. Moreover, in opposition to DFA0, an increase in the rubber amount for DFA0.3, DFA0.7 and DFA1 resulted in a significant enhancement in IS. The higher value of IS $\left(10.34 \mathrm{~kJ} . \mathrm{m}^{-2}\right)$ was obtained when DFA1 was used with an amount of $20 \mathrm{wt} \%$. It corresponds to an increase by a factor of 4.2 compared to neat PLLA.

Table 5. Mechanical properties of neat PLLA and the blends.

\begin{tabular}{cccccc} 
& & Yield stress & Strain at break & Notch IZOD IS \\
$(\mathbf{\%})$ & EModulus (Mpa) & $\begin{array}{c}\text { (MJ.m } \\
\mathbf{- 2})\end{array}$ \\
\hline & PLLA & $1510 \pm 304$ & $47.1 \pm 6.0$ & $3.8 \pm 1.4$ & $2.45 \pm 0.25$ \\
\hline 10wt\% & DFA0 & $788 \pm 61$ & $39.7 \pm 4.1$ & $385.3 \pm 124.2$ & $3.60 \pm 0.39$ \\
& DFA0.7 & $709 \pm 61$ & $33.4 \pm 0.9$ & $358.7 \pm 94.8$ & $6.12 \pm 0.83$ \\
& DFA1 & $988 \pm 42$ & $38.5 \pm 1.9$ & $62.6 \pm 31.7$ & $8.58 \pm 0.90$ \\
\hline & DFA0 & $765 \pm 128$ & $33.9 \pm 3.9$ & $21.2 \pm 8.2$ & $3.45 \pm 0.16$ \\
$\mathbf{2 0 w t \% o}$ & DFA0.3 & $880 \pm 61$ & $31.8 \pm 1.4$ & $126.0 \pm 47.6$ & $7.35 \pm 0.90$ \\
& DFA0.7 & $857 \pm 56$ & $30.0 \pm 1.9$ & $251.5 \pm 127.3$ & $9.96 \pm 1.27$ \\
& DFA1 & $809 \pm 54$ & $28.2 \pm 1.6$ & $17.2 \pm 7.1$ & $10.34 \pm 2.19$ \\
\hline
\end{tabular}

It is now well established, that in addition to the microstructure of the blend and the thermomechanical properties of the rubber, interfacial adhesion between the two phases plays a key role in the toughening efficiency of brittle materials. ${ }^{15,55}$ Due to the different chemical structures of the polyesters that were used in this study, interfacial adhesion has also to be taken into account in the toughening evaluation in addition to their crystallinity. Indeed, it was previously demonstrated that the solubility parameter of the polyester increases with the amount of DFA units. Thus, the higher compatibility of the DFA rich polyesters with PLLA is thought to also act toward high toughening efficiency due to a reinforced interface between the two phases. 
In order to identify the main toughening mechanisms occurring during impact testing, the impact-fractured surfaces were observed by SEM. The micrographs of all the blends are displayed in Figure S9 and the micrographs of the blends containing 20wt\% of rubber are displayed in Figure 8 and Figure S10.
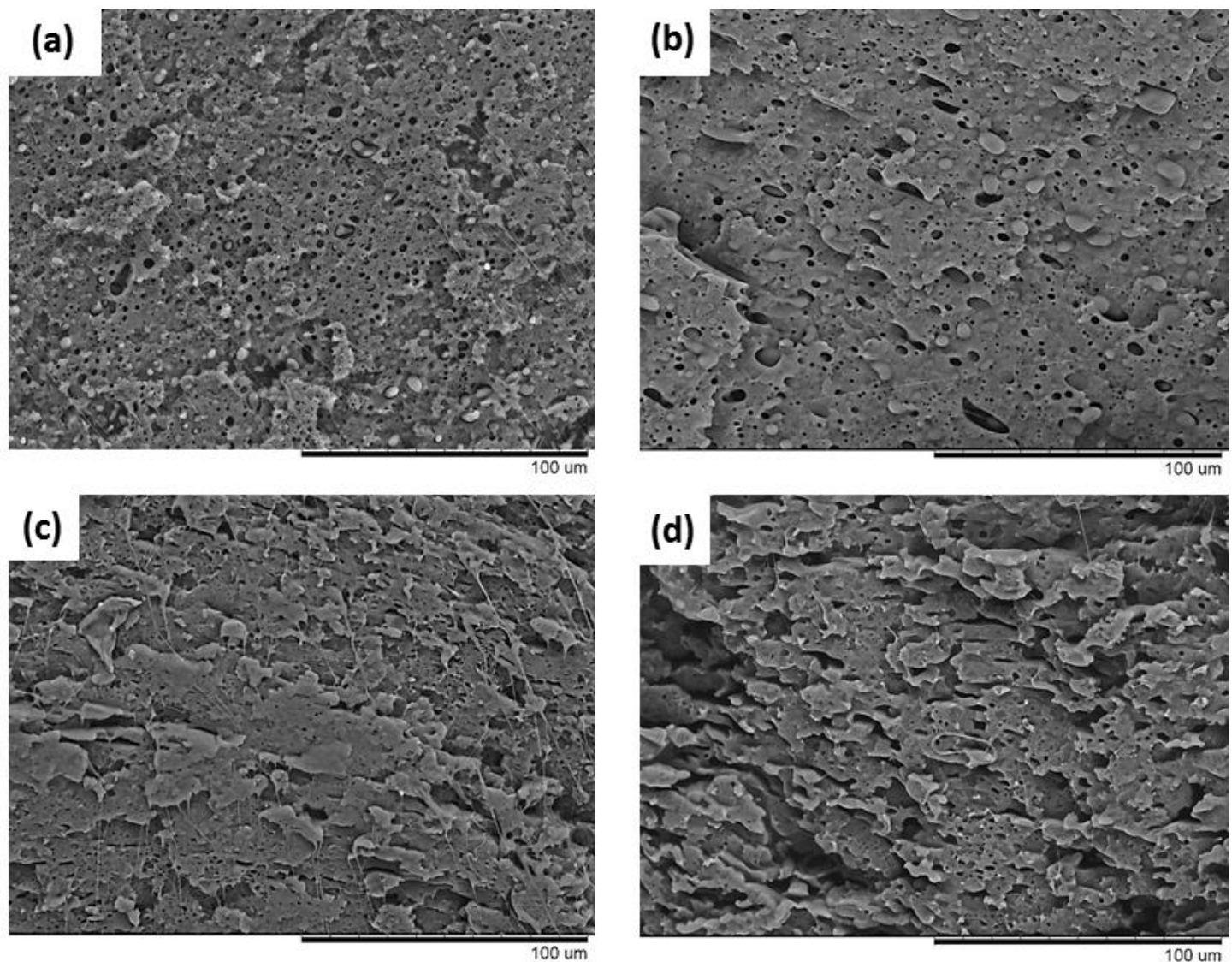

Figure 8. SEM images of the impact fractured surfaces of the blends with 20 wt $\%$ of polyester rubber (a) DFA0 (b) DFA0.3 (c) DFA0.7 (d) DFA1

The rubber-toughening mechanism is now well elucidated and is linked to the lower strength of the dispersed rubber phase in comparison to the PLLA matrix. The rubber particles, when subjected to impact stress, cavitate to produce voids which grow along the crack propagation and induce matrix shear yielding by stress concentration then leading to plastic deformation. ${ }^{56-59}$ 
Optimal impact strength of the blend is generally occurring when sufficient interfacial strength is observed and thus when internal cavitation is preferred as an initial step of the rubber-toughening mechanism. From Figure 8, various fractured surface morphologies can be observed. For the blend comprising $20 \mathrm{wt} \%$ of DFA0 (Fig 8a), a relatively smooth surface is observed with a little amount of fibrils and matrix deformation.

For the blends with DFA0.3 as a rubber (Fig $\mathbf{8 b}$ and Fig S10), the toughening mechanism seems to be quite different as the rubber particles are more elongated and more bonded to the matrix. The fractured surfaces of the blends with DFA0.7 and DFA1 as rubbers, showed higher deformation of the matrix with particles and voids more difficult to identify (Fig $\mathbf{8 c}$ and Fig 8d). This is attributed to the important plastic deformation and the coalescence of the largely elongated voids. Therefore internal cavitation is thought to be the predominant toughening mechanism for these samples in accordance with the low strength of DFA0.7 and DFA1 rubbers (in the melted state at the impact test temperature) and their better compatibility with PLLA (See solubility parameters in Table 1). This resulted in the optimum IS in our PLLA blend systems.

To summarize, two effects were investigated in the toughening of PLLA by the developed polyester rubbers. Indeed, the invariant glass transition of the different rubbers used allowed us to evaluate the influence of both the crystallinity degree of the rubbers and their compatibility with the PLLA matrix on the impact resistance of the blends. It was shown that the selection of a rubber showing low or no crystallinity and having good affinity with the PLLA matrix is needed to obtain optimal IS of the blends. By selecting the appropriate rubber, internal cavitation is predominant over interfacial cavitation which allows higher matrix shear yielding and thus higher ductility of the material. 


\section{CONCLUSION}

A set of novel aliphatic polyesters were prepared from plant oils based building blocks, namely sebacic acid (SA), 1,10-decanediol and hydrogenated dimer fatty acid (DFA). By varying the alkyl dangling chains (provided by DFA units) density, a large range of thermo-mechanical properties were obtained similarly to the tuning of the properties for commercial olefin elastomers (ethylene-hexene and ethylene-octene copolymers). By this way, novel polyesters with melting points in the range -6 to $78^{\circ} \mathrm{C}$ were obtained. The invariant glass transition $(\approx-$ $50^{\circ} \mathrm{C}$ ) with the rubber type allowed us to evaluate the influence of two factors on the impact resistance of binary blends of the different rubbers with PLLA: the crystallinity of the rubber and its affinity with the PLLA matrix.

Moreover these polyesters induced an improved crystallization rate of PLLA phase in the blends compared to neat PLLA ( $\mathrm{t}_{1 / 2}$ fron $6.1 \mathrm{~min}$ to $1.2 \mathrm{~min}$ ). Tensile tests performed with the blends showed a ductile to brittle transition as seen from the distinct yielding which was followed with stable neck growth. Elongation at break as high as $385 \%$ was obtained compared to $3.8 \%$ for neat PLLA.

Impact resistance of the blends was evaluated by notched IZOD impact tests. At similar composition, impact strength (IS) gradually increased with a decrease in crystallinity degree of the rubber. It was attributed to differences in the toughening mechanisms which were linked to the strength of the rubber. Highly crystalline rubbers resulted in interfacial cavitation when subjected to impact due to higher strength of the rubber in comparison to adhesion strength between the two phases. On the contrary, melted rubbers or poorly crystalline rubbers dispersed in the PLLA matrix reacted to high loading by internal cavitation. In all cases, cavitation was 
followed by void formation, growing along the crack propagation and matrix shear yielding. Nevertheless optimal IS (improved by a factor 4.2 compared to neat PLLA) was obtained for the less crystalline rubbers which showed internal cavitation as initial step in the toughening mechanism. An increase in the amount of rubber into the material led to further improvement of the IS.

This study proved the importance of the rubber strength, which can be controlled through its crystallinity, and its affinity with the PLLA matrix, for the toughening of PLLA. The importance of these criteria was illustrated by using potentially biodegradable and bio-based aliphatic polyesters that were obtained from the polycondensation of cheap and commercially available plant oil-based building blocks. This work might open other opportunities for the development of efficient and environmental friendly second-generation bio-based impact modifiers for PLLA.

\section{EXPERIMENTAL}

Materials. Sebacic acid (SA) (98.0\%) was supplied by Alfa Aesar. 1,10-decanediol (98.0\%) and titanium isopropoxide (99.9\%) were obtained from Sigma-Aldrich. Hydrogenated Dimer Fatty Acid (DFA) (Pripol 1009) was kindly provided by CRODA (acid value 197 mg KOH/g). Poly(Llactide) (PLA) was kindly provided by PURAC (Netherlands) (Mn= $121 \mathrm{~kg} \cdot \mathrm{mol}^{-1}, \mathrm{D}=1.5$ as determined by size-exclusion chromatography in THF). All products and solvents (reagent grade) were used as received.

Measurements. All NMR experiments were performed at $298 \mathrm{~K}$ in $\mathrm{CDCl}_{3}$ on a Bruker Avance I NMR spectrometer operating at $400 \mathrm{MHz}$ and equipped with a Bruker multinuclear z-gradient direct probe head capable of producing gradients in the $\mathrm{z}$ direction with strength $53.5 \mathrm{G} \mathrm{cm}^{-1}$. Size exclusion chromatography (SEC) analyses were performed in THF $\left(40^{\circ} \mathrm{C}\right)$ on a PL-GPC 50 
plus Integrated SEC from Polymer laboratories-Varian with a series of four columns from TOSOH (TSKgel TOSOH: HXL-L (guard column 6,0mm ID x 4,0cm L); G4000HXL (7,8mm ID x 30,0cm L) ;G3000HXL (7,8mm ID x 30,0cm L) and G2000HXL (7,8mm ID x 30,0cm L)). The elution of the filtered samples was monitored using simultaneous refractive index and UV detection. The elution times were converted to molar mass using a calibration curve based on low dispersity $\left(\mathrm{M}_{\mathrm{w}} / \mathrm{M}_{\mathrm{n}}\right)$ polystyrene (PS) standards. Differential scanning calorimetry (DSC) thermograms were measured using a DSC Q100 apparatus from TA instruments. Each sample was first melted for $3 \mathrm{~min}$ at $200^{\circ} \mathrm{C}$ to remove previous thermal history. Non-isothermal crystallization behaviors were evaluated by cooling the samples to $-80^{\circ} \mathrm{C}$ at $10^{\circ} \mathrm{C} \cdot \mathrm{min}^{-1}$ and reheating up to $200^{\circ} \mathrm{C}$ at $10^{\circ} \mathrm{C} \cdot \mathrm{min}^{-1}$. Measurement of the glass transition temperature (Tg), cold crystallization temperature (Tcc) and melting temperature (Tm) was then performed. Isothermal crystallization investigation was performed by rapid cooling $\left(50^{\circ} \mathrm{C} \cdot \mathrm{min}^{-1}\right)$ of the samples from the melt to $110^{\circ} \mathrm{C}$ and by keeping the samples at this temperature for $30 \mathrm{~min}$. The exothermic curves of heat flow as a function of time were recorded. Thermogravimetric analyses (TGA) were performed on TGA-Q50 system from TA instruments at a heating rate of $10{ }^{\circ} \mathrm{C} . \mathrm{min}^{-1}$ under nitrogen atmosphere. The visco-elastic properties of the copolymers were recorded by a dynamic mechanical analyzer (DMA), a model RSA-III apparatus from TA Instruments equipped with a liquid nitrogen cooling system. Forced strain was used on a rectangular tensile geometry at a frequency of $1 \mathrm{~Hz}$, a strain of $0.1 \%$ and a temperature range between $-80{ }^{\circ} \mathrm{C}$ and $\mathrm{T}_{\mathrm{m}}+15{ }^{\circ} \mathrm{C}$ at a rate of $5{ }^{\circ} \mathrm{C} \cdot \mathrm{min}^{-1}$. To determine the mechanical properties of the polymers, tensile stress and tensile strain were obtained using DMA apparatus in traction transient mode at a rate of $10 \mathrm{~mm} \cdot \mathrm{min}^{-1}$. Tensile tests were performed on polymers processed into films using a simple hotpress technique. The effective length, width, and thickness of the specimens were $10,2.5$, and 
$0.5 \mathrm{~mm}$, respectively. Tensile tests were carried out after the processed specimens were let overnight at room temperature. An average value of seven replicated measurements was taken for each sample. Notched Izod impact tests were performed according to ASTM D256 using an AIS multi impact XJF-5.5 pendulum impact tester. The rheological properties of the blends in the molten state were assessed using a parallel-plate $(d=25 \mathrm{~mm})$ rheometer (AR 2000 rheometer from TA instruments). The sample was loaded between the parallel plates and melted at $190{ }^{\circ} \mathrm{C}$ for $3 \mathrm{~min}$. The parallel plates subsequently compressed the sample to $1.000 \mathrm{~mm}$ thick prior to each test. A dynamic frequency sweep test was performed to determine the viscoelastic properties of the blends. The strain and frequency range used during testing were 5\% and 5000.05 rad.s ${ }^{-1}$, respectively. Complex viscosity $\left(\eta^{*}\right)$, storage modulus $\left(G^{\prime}\right)$, and loss modulus $\left(G^{\prime \prime}\right)$ in the molten state were obtained.

\section{Polyesters synthesis}

All monomers were dried at $70^{\circ} \mathrm{C}$ under vacuum overnight prior to use. Stoichiometric mixture of Sebacic acid, DFA, 1,10-decanediol (-COOH/-OH=1) and titanium isopropoxide (0.1 wt\%) was stirred at $180^{\circ} \mathrm{C}$ under a dynamic nitrogen flow. After $1 \mathrm{~h}$, dynamic vacuum was applied. After $1 \mathrm{~h}$, the temperature was then raised to $200^{\circ} \mathrm{C}$ for 4 hours and subsequently raised to $220^{\circ} \mathrm{C}$ for 2 hours. After completion of the reaction, the polyester was cooled down to room temperature.

${ }^{1} \mathrm{H}-\mathrm{NMR}\left(400 \mathrm{MHz}, \mathrm{CDCl}_{3}, \delta\right.$ ): 0.88 (m, - $\left.\mathrm{CH}_{2}-\mathrm{CH}_{3}\right), 1.00-1.40$ (m, -[CH $\left.\mathrm{CH}_{2}\right]$ ), 1.60 (t, -COO$\left.\mathrm{CH}_{2}-\mathrm{CH}_{2}-\right), 2.28$ (t, - $\left.\mathrm{CH}_{2}-\mathrm{COO}-\right), 4.04$ (t, - $\left.\mathrm{COO}-\mathrm{CH}_{2}-\mathrm{CH}_{2}-\right)$.

\section{Blend preparation}

Prior to extrusion, PLLA pellets were dried at least $12 \mathrm{~h}$ at $80^{\circ} \mathrm{C}$ in an oven under reduced pressure. Melt-blending of the rubbers with PLLA was realized using a DSM twin-screw micro- 
compounder $(5 \mathrm{cc})$ at $190^{\circ} \mathrm{C}$ and $50 \mathrm{rpm}$ for 5 minutes. Impact test bars (dimensions $12.7 \times 50 \times$ $3.2 \mathrm{~mm}$ ) were prepared by injection molding at $200^{\circ} \mathrm{C}$ in a mold kept at $50^{\circ} \mathrm{C}$. The test bars were remain overnight at room temperature. In order to prevent further aging before their analysis, the test bars were then stored at $4^{\circ} \mathrm{C}$.

\section{ASSOCIATED CONTENT}

Supporting Information. Figure showing TGA and DSC of the polyester and melt-rheology, TGA, Avrami Plot, Stress-Strain curves and SEM of the polyester/PLLA blends.

\section{AUTHOR INFORMATION}

\section{Corresponding Author}

*cramail@enscbp.fr

\section{ACKNOWLEDGMENT}

The authors thank Patrick Garrigue for SEM imaging (Nsysa-ISM, University of BordeauxCNRS). The authors also thank Gérard Dimier and Emmanuel Ibarboure for fruitful discussions. This study was financially supported by the University of Bordeaux-1, ANR, IPB, CNRS, Aquitaine Council, ITERG, ONIDOL and ADEME agency.

\section{REFERENCES}

1. Mülhaupt, R. Green Polymer Chemistry and Bio-based Plastics: Dreams and Reality. Macromol. Chem. Phys. 2013, 214, 159-174.

2. Dodds, D. R.; Gross, R. A. Chemicals from biomass. Science 2007, 318, 1250-1251. 
3. Gandini, A. The irruption of polymers from renewable resources on the scene of macromolecular science and technology. Green Chem. 2011, 13, 1061-1083.

4. Gandini, A. Polymers from Renewable Resources: A Challenge for the Future of Macromolecular Materials. Macromolecules 2008, 41, 9491-9504.

5. European Bioplastics. http://en.european-bioplastics.org/ (accessed Nov 7, 2014).

6. Zhang, X.; Li, Y.; Han, L.; Han, C.; Xu, K.; Zhou, C.; Zhang, M.; Dong, L. Improvement in toughness and crystallization of poly(L-lactic acid) by melt blending with ethylene/methyl acrylate/glycidyl methacrylate terpolymer. Polymer Eng. Sci. 2013, 53, 2498-2508.

7. John, R.; Nampoothiri, K. M.; Pandey, A. Fermentative production of lactic acid from biomass: an overview on process developments and future perspectives. Appl. Microbiol. Biotechnol. 2007, 74, 524-534.

8. Jérôme, C.; Lecomte, P. Recent advances in the synthesis of aliphatic polyesters by ringopening polymerization. Adv. Drug Deliv. Rev. 2008, 60, 1056-1076.

9. Madhavan Nampoothiri, K.; Nair, N. R.; John, R. P. An overview of the recent developments in polylactide (PLA) research. Bioresource Technol. 2010, 101, 8493-8501.

10. Gupta A. P.; Kumar, V. New emerging trends in synthetic biodegradable polymers Polylactide: A critique. Europ. Polym. J. 2007, 43, 4053-4074.

11. Garlotta, D. A Literature Review of Poly(Lactic Acid). J. Polym. Environ. 2001, 9, 6384. 
12. Auras, R.; Harte, B.; Selke, S. An Overview of Polylactides as Packaging Materials. Macromol. Biosci. 2004, 4, 835-864.

13. Södergård, A.; Stolt, M. Properties of lactic acid based polymers and their correlation with composition. Prog. Polym. Sci. 2002, 27, 1123-1163.

14. Anderson, K. S.; Schreck, K. M.; Hillmyer, M. A. Toughening polylactide. Polym. Rev. $2008,48,85-108$.

15. Liu H.; Zhang, J. Research progress in toughening modification of poly(lactic acid) (PLA). J. Polym. Sci. Pol. Phys. 2011, 49, 1051-1083.

16. Becker, J. M.; Pounder, R. J.; Dove, A. P. Synthesis of Poly(lactide)s with Modified Thermal and Mechanical Properties. Macromol. Rapid Commun. 2010, 31, 1923-1937.

17. NatureWorks. Technology Focus Report: Toughened PLA. http://www.natureworksllc.com/ /media/Technical_Resources/Technical_Publications/White_Pa pers/Toughened-PLA-Technology-Focus-pdf.pdf (accessed Nov 7, 2014).

18. Anderson, K. S.; Lim, S. H.; Hillmyer, M. A. Toughening of polylactide by melt blending with linear low-density polyethylene. J. Appl. Polym. Sci. 2003, 89, 3757-3768.

19. Anderson, K. S.; Hillmyer, M. A. The influence of block copolymer microstructure on the toughness of compatibilized polylactide/polyethylene blends. Polymer 2004, 45, 8809-8823.

20. Feng, Y.; Hu, Y.; Yin, J.; Zhao, G.; Jiang, W. High impact poly(lactic acid)/poly(ethylene octene) blends prepared by reactive blending. Polymer Eng. Sci. 2013, 53, 389-396. 
21. Ma, P.; Hristova-Bogaerds, D. G.; Goossens, J. G. P.; Spoelstra, A. B.; Zhang, Y.; Lemstra, P. J. Toughening of poly(lactic acid) by ethylene-co-vinyl acetate copolymer with different vinyl acetate contents. Europ. Polym. J. 2012, 48, 146-154.

22. Meng, B.; Deng, J.; Liu, Q.; Wu, Z.; Yang, W. Transparent and ductile poly(lactic acid)/poly(butyl acrylate) (PBA) blends: Structure and properties. Europ. Polym. J. 2012, 48, $127-135$.

23. Petchwattana, N.; Covavisaruch, S.; Euapanthasate, N. Utilization of ultrafine acrylate rubber particles as a toughening agent for poly(lactic acid). Mat. Sci. Eng. A-Struct. 2012, 532, $64-70$.

24. Hashima, K.; Nishitsuji, S.; Inoue, T. Structure-properties of super-tough PLA alloy with excellent heat resistance. Polymer 2010, 51, 3934-3939.

25. Qi, R.; Luo, M.; Huang, M. Synthesis of styrene-ethylene-butylene-styrene triblock copolymer-g-polylactic acid copolymer and its potential application as a toughener for polylactic acid. J. Appl. Polym. Sci. 2011, 120, 2699-2706.

26. Li, Y.; Shimizu, H. Improvement in Toughness of Poly(L-Lactide) (PLLA) through Reactive Blending with Acrylonitrile-Butadiene-Styrene Copolymer (ABS): Morphology and Properties. Europ. Polym. J. 2009, 45, 738-746.

27. Liu, H.; Chen, F.; Liu, B.; Estep, G.; Zhang, J. Super Toughened Poly(lactic acid) Ternary Blends by Simultaneous Dynamic Vulcanization and Interfacial Compatibilization. Macromolecules 2010, 43, 6058-6066. 
28. Liu, H.; Song, W.; Chen, F.; Guo, L.; Zhang, J. Interaction of Microstructure and Interfacial Adhesion on Impact Performance of Polylactide (PLA) Ternary Blends. Macromolecules 2011, 44, 1513-1522.

29. Su, Z.; Li, Q.; Liu, Y.; Hu, G.-H.; Wu, C. Compatibility and phase structure of binary blends of poly(lactic acid) and glycidyl methacrylate grafted poly(ethylene octane). Europ. Polym. J. 2009, 45, 2428-2433.

30. Zhang, X.; Li, Y.; Han, L.; Han, C.; Xu, K.; Zhou, C.; Zhang, M.; Dong, L. Improvement in toughness and crystallization of poly(L-lactic acid) by melt blending with ethylene/methyl acrylate/glycidyl methacrylate terpolymer. Polymer Eng. Sci. 2013, 53, 2498-2508.

31. López-Rodríguez, N.; López-Arraiza, A.; Meaurio, E.; Sarasua, J. R. Crystallization, morphology, and mechanical behavior of polylactide/poly( $\varepsilon$-caprolactone) blends. Polymer Eng. Sci. 2006, 46, 1299-1308.

32. Wang, L.; Ma, W.; Gross, R. A.; McCarthy, S. P. Reactive compatibilization of biodegradable blends of poly(lactic acid) and poly(E-caprolactone). Polym. Degrad. Stabil. 1998, 59, 161-168.

33. Harada, M.; Iida, K.; Okamoto, K.; Hayashi, H.; Hirano, K. Reactive compatibilization of biodegradable poly(lactic acid)/poly( $\varepsilon$-caprolactone) blends with reactive processing agents. Polymer Eng. Sci. 2008, 48, 1359-1368.

34. Semba, T.; Kitagawa, K.; Ishiaku, U. S.; Hamada, H. The effect of crosslinking on the mechanical properties of polylactic acid/polycaprolactone blends. J. Appl. Polym. Sci. 2006, 101, 1816-1825. 
35. Odent, J.; Leclère, P.; Raquez, J.-M.; Dubois, P. Toughening of polylactide by tailoring phase-morphology with $\mathrm{P}[\mathrm{CL}-\mathrm{co}-\mathrm{LA}]$ random copolyesters as biodegradable impact modifiers. Europ. Polym. J. 2013, 49, 914-922.

36. Wang, R.; Wang, S.; Zhang, Y.; Wan, C.; Ma, P. Toughening modification of PLLA/PBS blends via in situ compatibilization. Polym. Eng. Sci. 2009, 49, 26-33.

37. Harada, M.; Ohya, T.; Iida, K.; Hayashi, H.; Hirano, K.; Fukuda, H. Increased impact strength of biodegradable poly(lactic acid)/poly(butylene succinate) blend composites by using isocyanate as a reactive processing agent. J. Appl. Polym. Sci. 2007, 106, 1813-1820.

38. Zhang, N.; Wang, Q.; Ren, J.; Wang, L. Preparation and properties of biodegradable poly(lactic acid)/poly(butylene adipate-co-terephthalate) blend with glycidyl methacrylate as reactive processing agent. J. Mat. Sci. 2009, 44, 250-256.

39. Jiang, L.; Wolcott, M. P.; Zhang, J. Study of Biodegradable Polylactide/Poly(butylene adipate-co-terephthalate) Blends. Biomacromolecules, 2005, 7, 199-207.

40. Schreck, K. M.; Hillmyer, M. A. Block copolymers and melt blends of polylactide with Nodax $^{\mathrm{TM}}$ microbial polyesters: Preparation and mechanical properties. J. Biotechnol. 2007, 132, 287-295.

41. Noda, I.; Satkowski, M. M.; Dowrey, A. E.; Marcott, C. Polymer Alloys of Nodax Copolymers and Poly(lactic acid). Macromol. Biosci. 2004, 4, 269-275.

42. Takagi, Y.; Yasuda, R.; Yamaoka, M.; Yamane, T. Morphologies and mechanical properties of polylactide blends with medium chain length poly(3-hydroxyalkanoate) and chemically modified poly(3-hydroxyalkanoate). J. Appl. Polym. Sci. 2004, 93, 2363-2369. 
43. Wei, T.; Lei, L.; Kang, H.; Qiao, B.; Wang, Z.; Zhang, L.; Coates, P.; Hua, K.-C.; Kulig, J. Tough Bio-Based Elastomer Nanocomposites with High Performance for Engineering Applications. Adv. Eng. Mat. 2012, 14, 112-118.

44. Kang, H.; Qiao, B.; Wang, R.; Wang, Z.; Zhang, L.; Ma, J.; Coates, P. Employing a novel bioelastomer to toughen polylactide. Polymer 2013, 54, 2450-2458.

45. Odent, J.; Raquez, J.-M.; Duquesne, E.; Dubois, P. Random aliphatic copolyesters as new biodegradable impact modifiers for polylactide materials. Europ. Polym. J. 2012, 48, 331-340.

46. Petrović, Z. S. Polyurethanes from Vegetable Oils. Polym. Rev. 2008, 48, 109-155.

47. Meier, M. A. R.; Metzger, J. O.; Schubert, U. S. Plant oil renewable resources as green alternatives in polymer science. Chem. Soc. Rev. 2007, 36, 1788-1802.

48. Montero de Espinosa, L.; M. A. R. Meier, M. A. R. Plant Oils: The Perfect Renewable Resource for Polymer Science. Europ. Polym. J. 2011, 47, 837-852.

49. Maisonneuve, L.; Lebarbé, T.; Grau, E.; Cramail, H. Structure-properties relationship of fatty acid-based thermoplastics as synthetic polymer mimics. Polym. Chem. 2013, 4, 5472-5517.

50 Stefanis, E.; Panayiotou, C. Prediction of Hansen Solubility Parameters with a New Group-Contribution Method. Int. J. Thermophysics 2008, 29, 568-585.

51 Pan, P.; Zhu, B.; Inoue, Y. Enthalpy Relaxation and Embrittlement of Poly(1-lactide) during Physical Aging. Macromolecules 2007, 40, 9664-9671.

52 Zhang, T.; Hu, J.; Duan, Y.; Pi, F.; Zhang, J. Physical Aging Enhanced Mesomorphic Structure in Melt-Quenched Poly(1-lactic acid). J. Phys. Chem. B 2011, 115, 13835-13841. 
53. Zhang, J.; Tashiro, K.; Tsuji, H.; Domb, A. J. Disorder-to-Order Phase Transition and Multiple Melting Behavior of Poly(l-lactide) Investigated by Simultaneous Measurements of WAXD and DSC. Macromolecules 2008, 41, 1352-1357.

54. Miyata, T.; T. Masuko, T. Crystallization behaviour of poly(1-lactide). Polymer 1998, 39, $5515-5521$.

55. $\mathrm{Wu}, \mathrm{S}$. Phase structure and adhesion in polymer blends: A criterion for rubber toughening. Polymer 1985, 26, 1855-1863.

56. Argon, A. S.; Cohen, R. E. Toughenability of polymers. Polymer 2003, 44, 6013-6032.

57. Bucknall, C. B. Quantitative approaches to particle cavitation, shear yielding, and crazing in rubber-toughened polymers. J. Polym. Sci. Pol. Phys. 2007, 45, 1399-1409.

58. Mahajan, D. K.; Hartmaier, A. Mechanisms of crazing in glassy polymers revealed by molecular dynamics simulations. Phys. Rev. E 2012, 86, 021802.

59. Kowalczyk, M.; Piorkowska, E. Mechanisms of plastic deformation in biodegradable polylactide/poly(1,4-cis-isoprene) blends. J. Appl. Polym. Sci. 2012, 124, 4579-4589. 
For Table of Contents Graphic only

Synthesis of Fatty acid-based polyesters and their blends with Poly(L-Lactide) as a way to tailor PLLA toughness

Thomas Lebarbé, Etienne Grau, Benoit Gadenne, Carine Alfos and Henri Cramail*

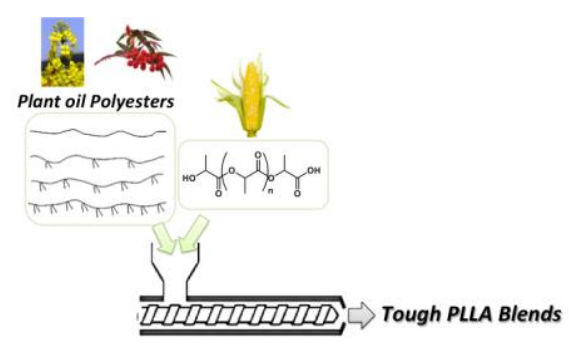

Melt-blending of PLLA (poly-L-lactide) with fatty acid-based flexible polyesters as an efficient way to tailor PLLA toughness. 


\section{Synthesis of Fatty acid-based polyesters and their blends with Poly(L-Lactide) as a way to tailor PLLA}

\section{toughness.}

Thomas Lebarbé, ${ }^{1,24}$ Etienne Grau, ${ }^{1,2}$ Benoit Gadenne, ${ }^{3}$ Carine Alfos ${ }^{3}$ and Henri Cramail ${ }^{* 1,2}$

${ }^{1}$ Université de Bordeaux, Laboratoire de Chimie des Polymères Organiques, ENSCBP, 16 Avenue Pey-Berland, Pessac Cedex, F 33607 France.

${ }^{2}$ CNRS, Laboratoire de Chimie des Polymères Organiques, Pessac Cedex, F 33607, France.

${ }^{3}$ ITERG, 11 rue Gaspard Monge, Parc Industriel, Pessac Cedex, F 33600, France.

${ }^{4}$ French Environment and Energy Management Agency, 20 avenue du Grésillé-BP 90406, AngersCedex 01, F 49004, France 
Table S1. Thermal degradation data of PLLA and the polyesters- $10^{\circ} \mathrm{C} \cdot \mathrm{min}^{-1}$.

\begin{tabular}{cccc} 
& $\mathbf{T}_{5 \%}\left({ }^{\circ} \mathrm{C}\right)$ & $\mathbf{T}_{\max }\left({ }^{\circ} \mathrm{C}\right)$ & $\begin{array}{c}\text { Residue } \\
\text { (\%) }\end{array}$ \\
\hline PLLA & 334.9 & 407.1 & 1.3 \\
DFA0 & 337.9 & 486.3 & 1.1 \\
DFA0.3 & 389.1 & 486.9 & 1.1 \\
DFA0.7 & 398.7 & 492.9 & 0.5 \\
DFA1 & 394.1 & 486.9 & 1.7
\end{tabular}
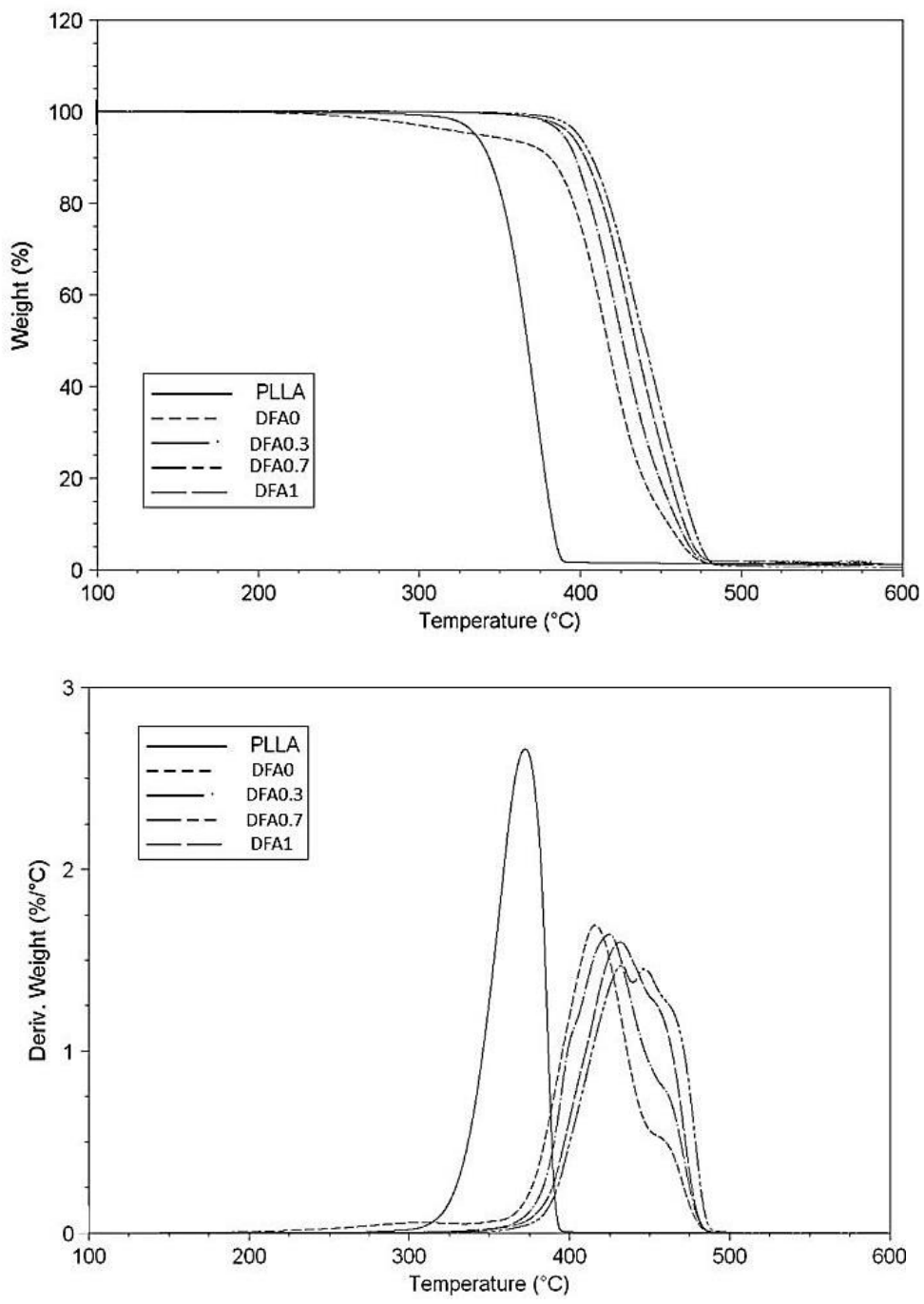

Figure S1. TGA and TGA derivative curves of PLLA and the polyesters- $10^{\circ} \mathrm{C} \cdot \mathrm{min}^{-1}$. 


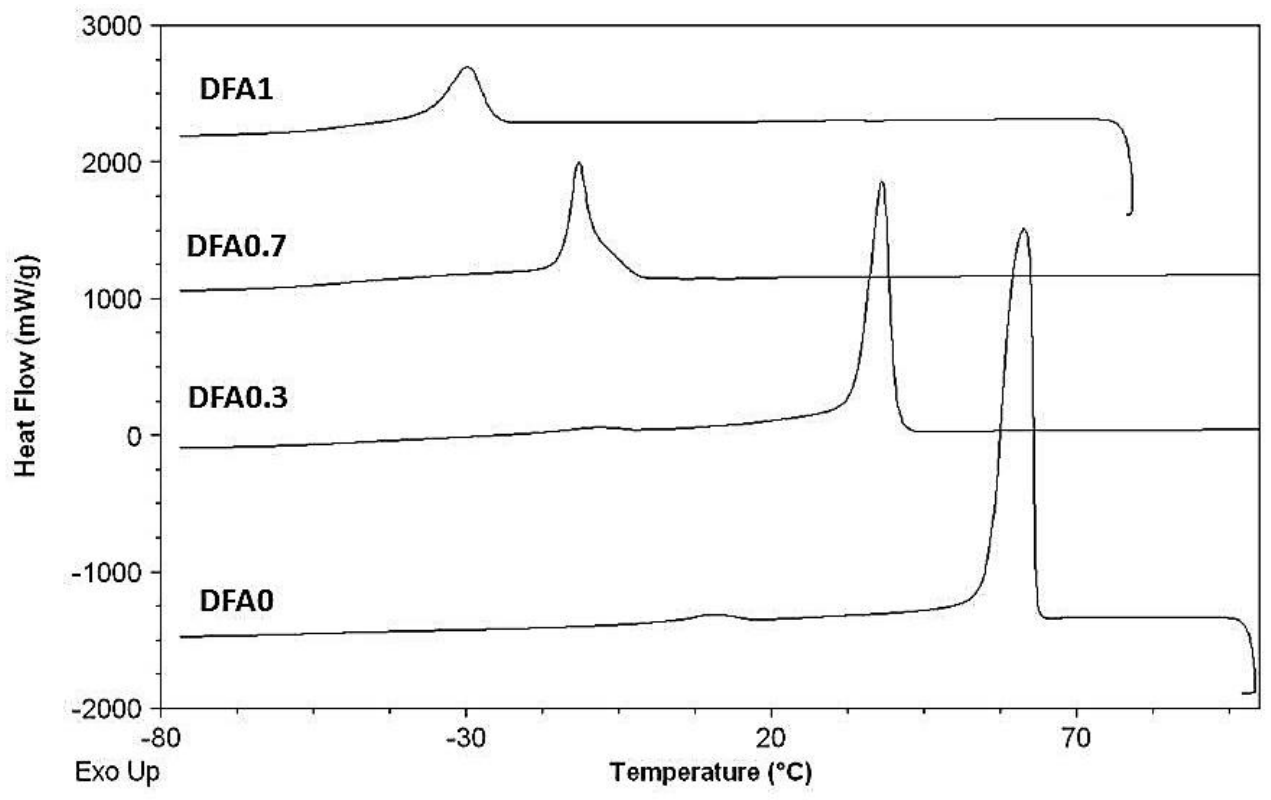

Figure S2. DSC cooling scan of the polyesters $-10^{\circ} \mathrm{C} \cdot \mathrm{min}^{-1}$.

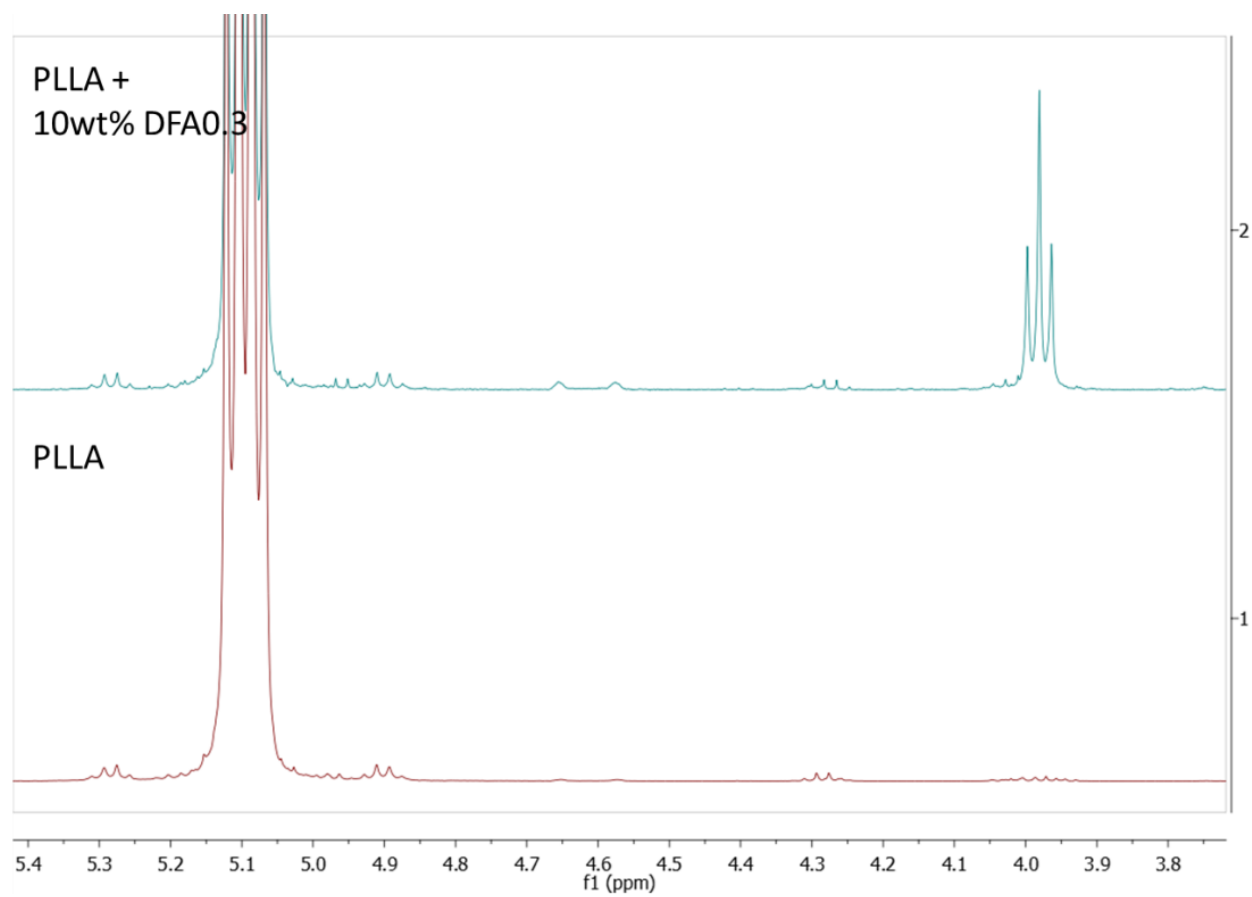

Figure S3. ${ }^{1} \mathrm{H}-\mathrm{NMR}$ stacked spectra of PLLA and PLLA/DFA0.3 blend in $\mathrm{CDCl}_{3}$ in between 5.4-3.7 ppm. 


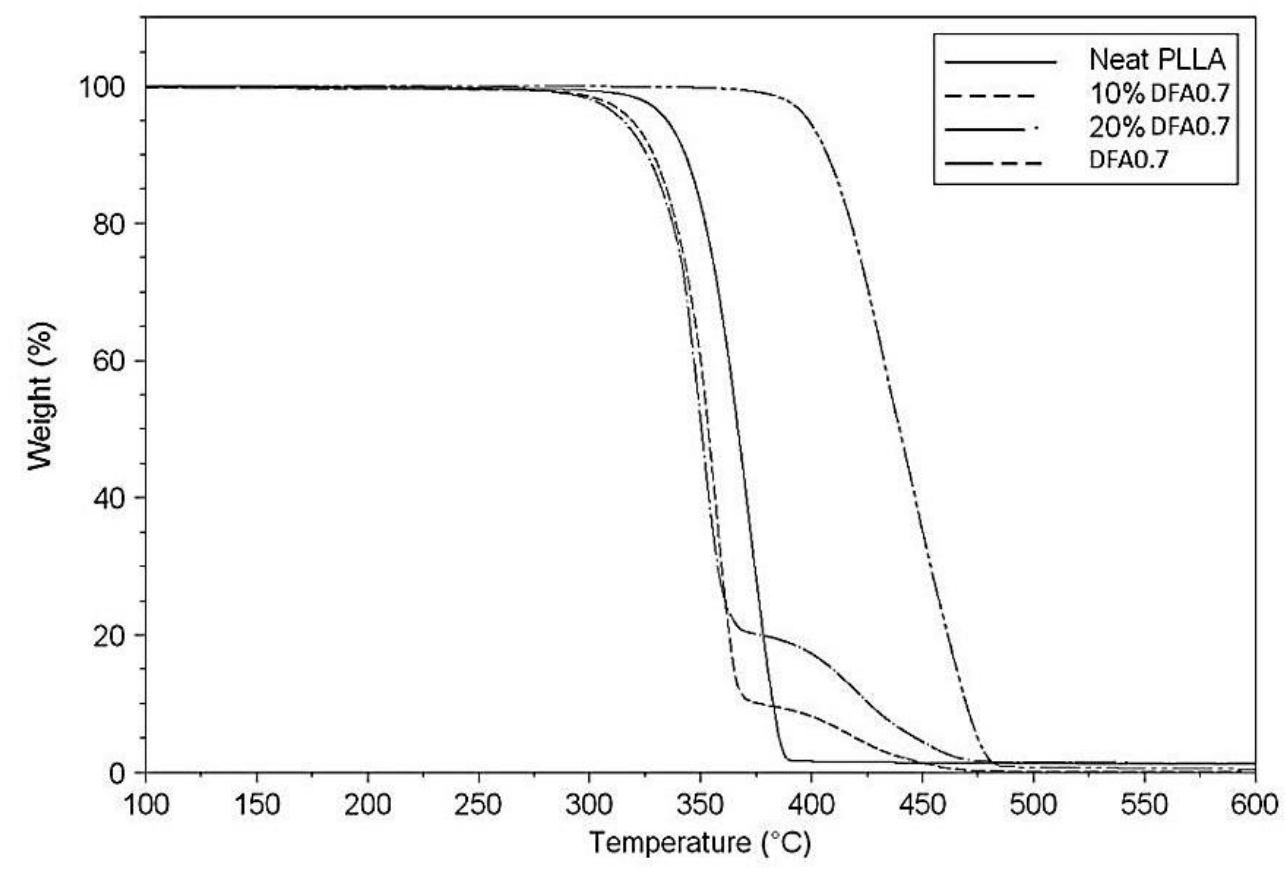

Figure S4. TGA curves of the neat PLLA, DFA0.7 and PLLA/DFA0.7 blends- $10^{\circ} \mathrm{C} . \mathrm{min}^{-1}$.
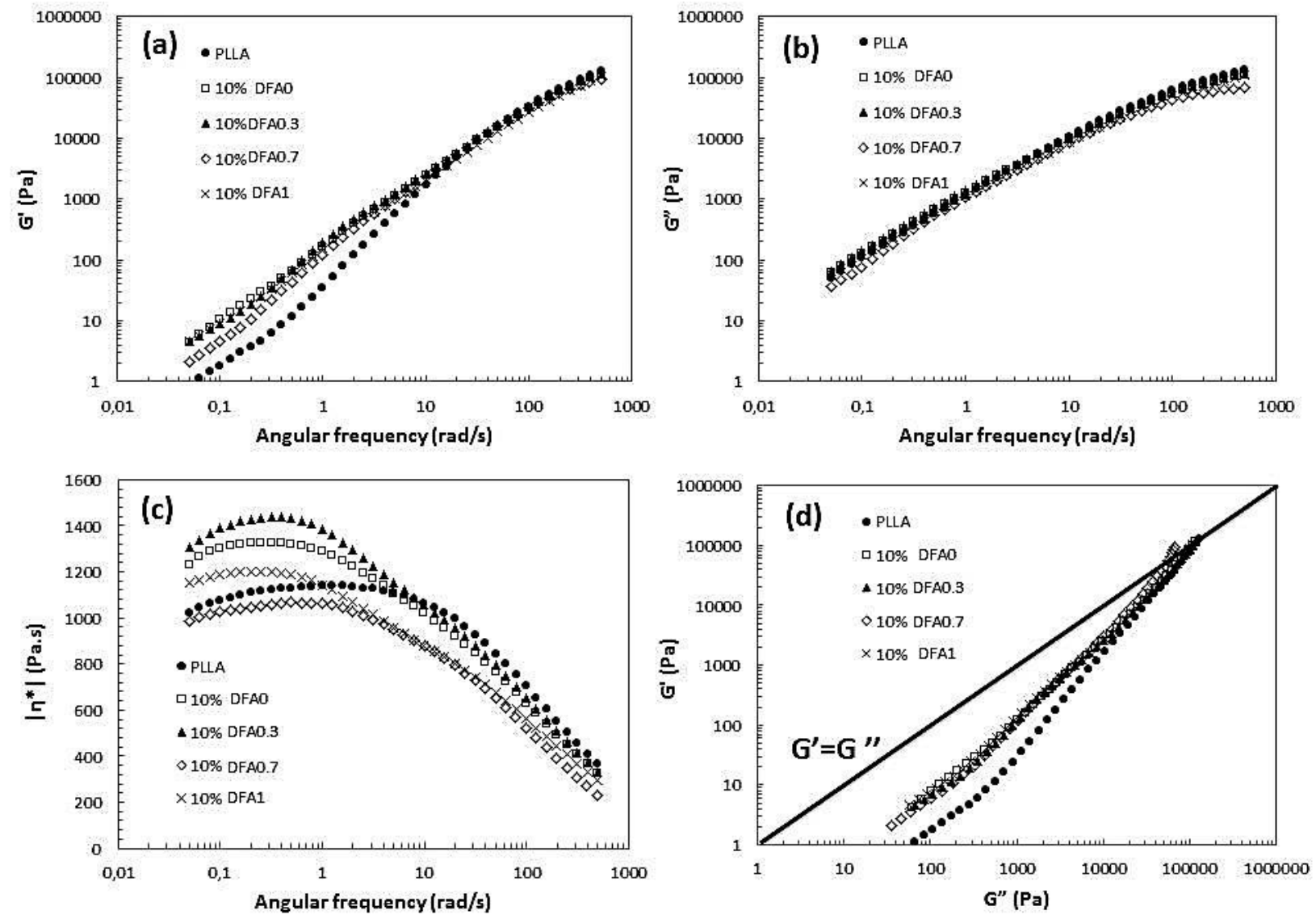
Figure S5. (a) Storage modulus, (b) loss modulus, (c) complex viscosity of neat PLLA and the PLLA/Rubber (90/10: w/w) blends as a function of angular frequency. (d) Han plot showing the storage modulus versus the loss modulus. All measurements were performed at $190^{\circ} \mathrm{C}$ using a strain deformation of $5 \%$.
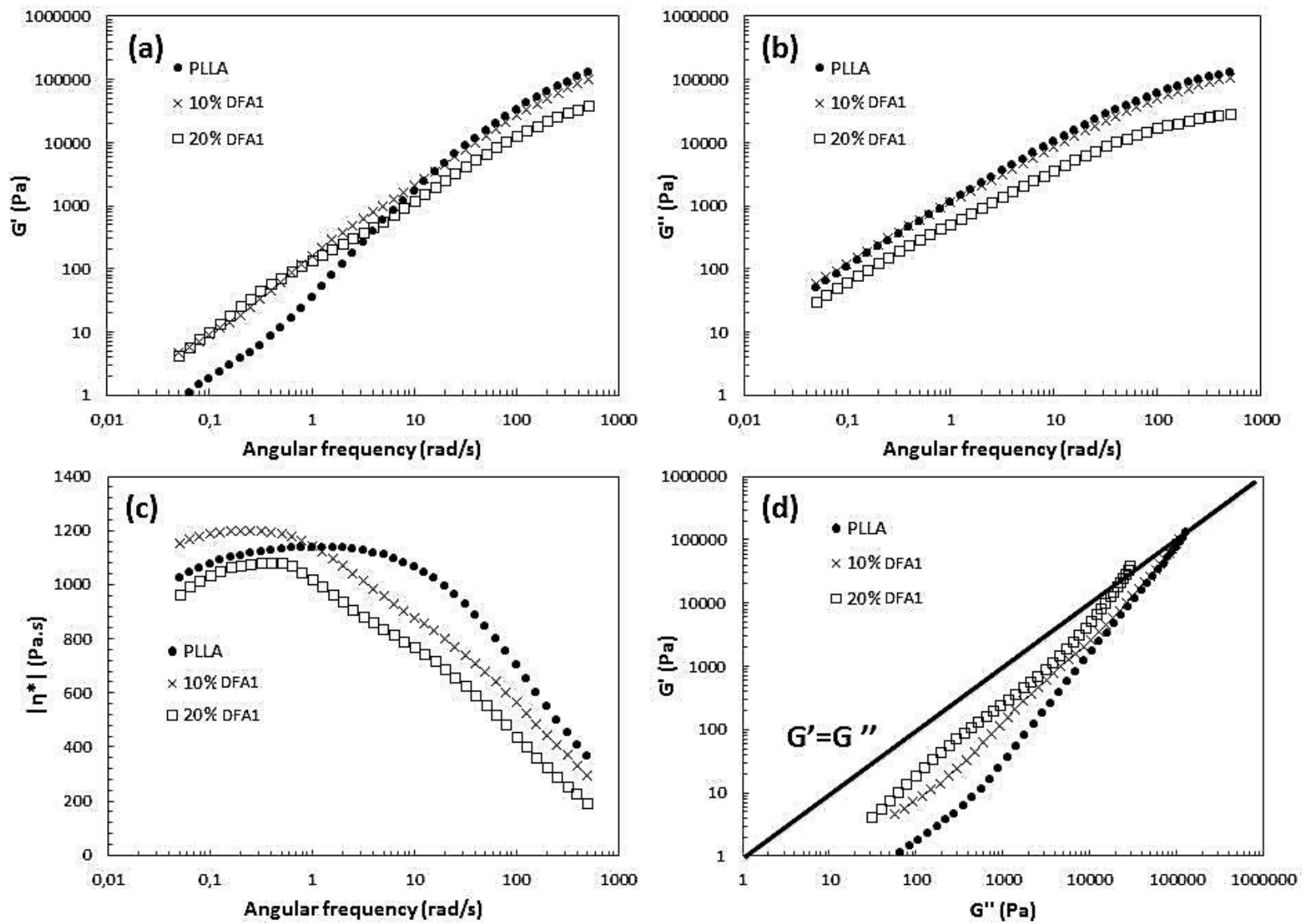

Figure S6. (a) Storage modulus, (b) loss modulus, (c) complex viscosity of neat PLLA and the PLLA/DFA1 blends as a function of angular frequency. (d) Han plot showing the storage 
modulus versus the loss modulus. All measurements were performed at $190^{\circ} \mathrm{C}$ using a strain deformation of $5 \%$.

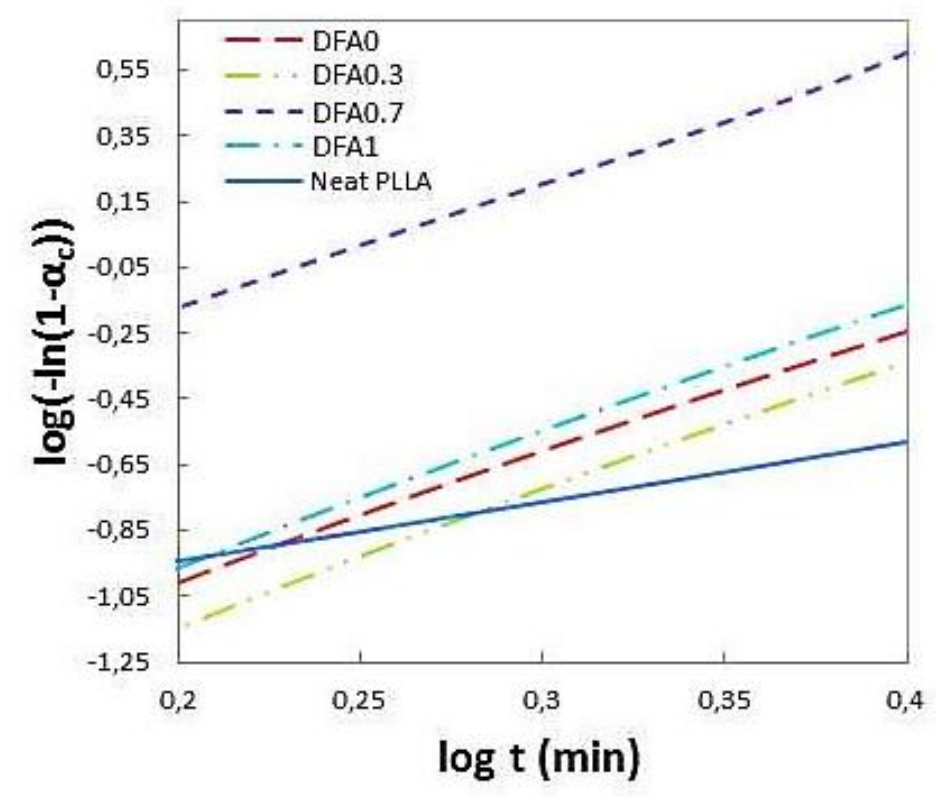

Figure S7. Avrami plot - Effect of the rubber type on isothermal crystallization $\left(110^{\circ} \mathrm{C}\right)$ of PLLA phase in $10 \mathrm{wt} \%$ blends. 


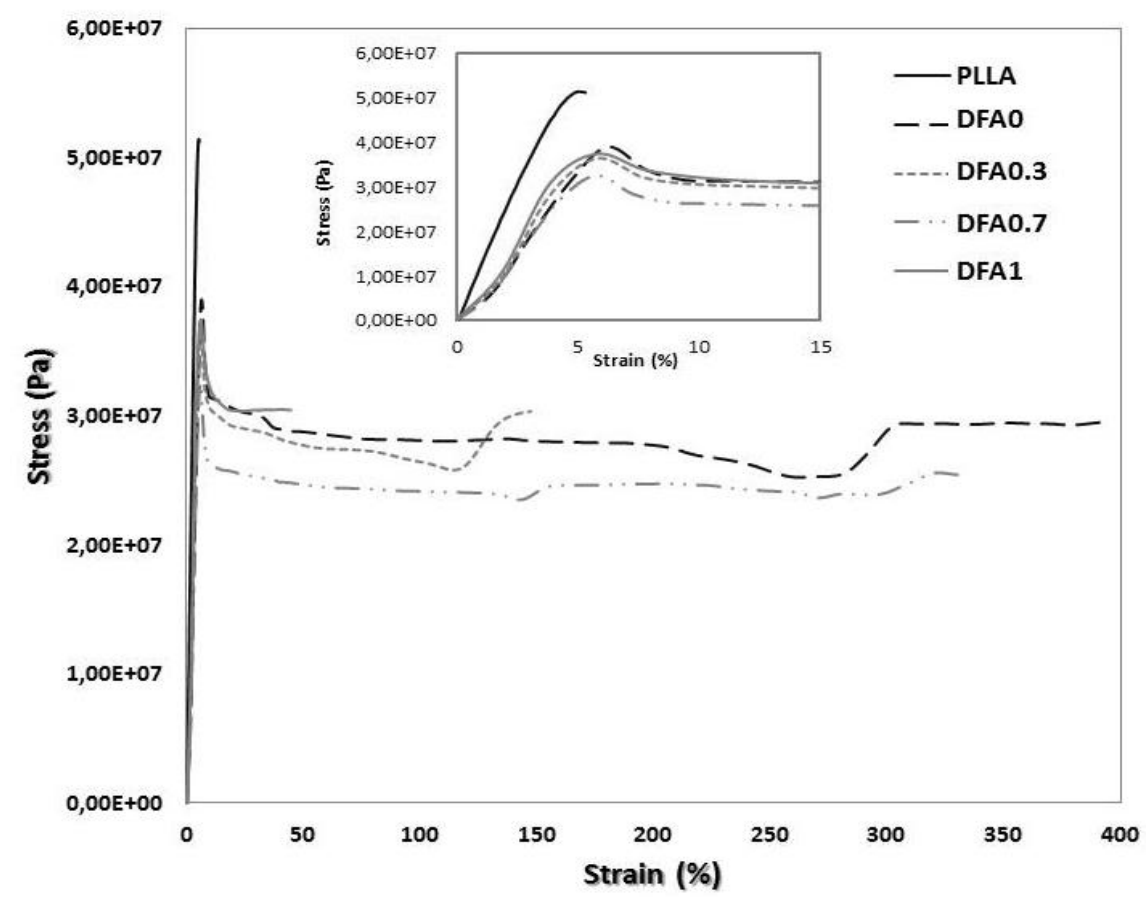

Figure S8. Stress-strain curves for neat PLLA and the blends containing $10 \mathrm{wt} \%$ of rubber.

$$
\mathrm{v}=10 \mathrm{~mm} \cdot \mathrm{min}^{-1} .
$$



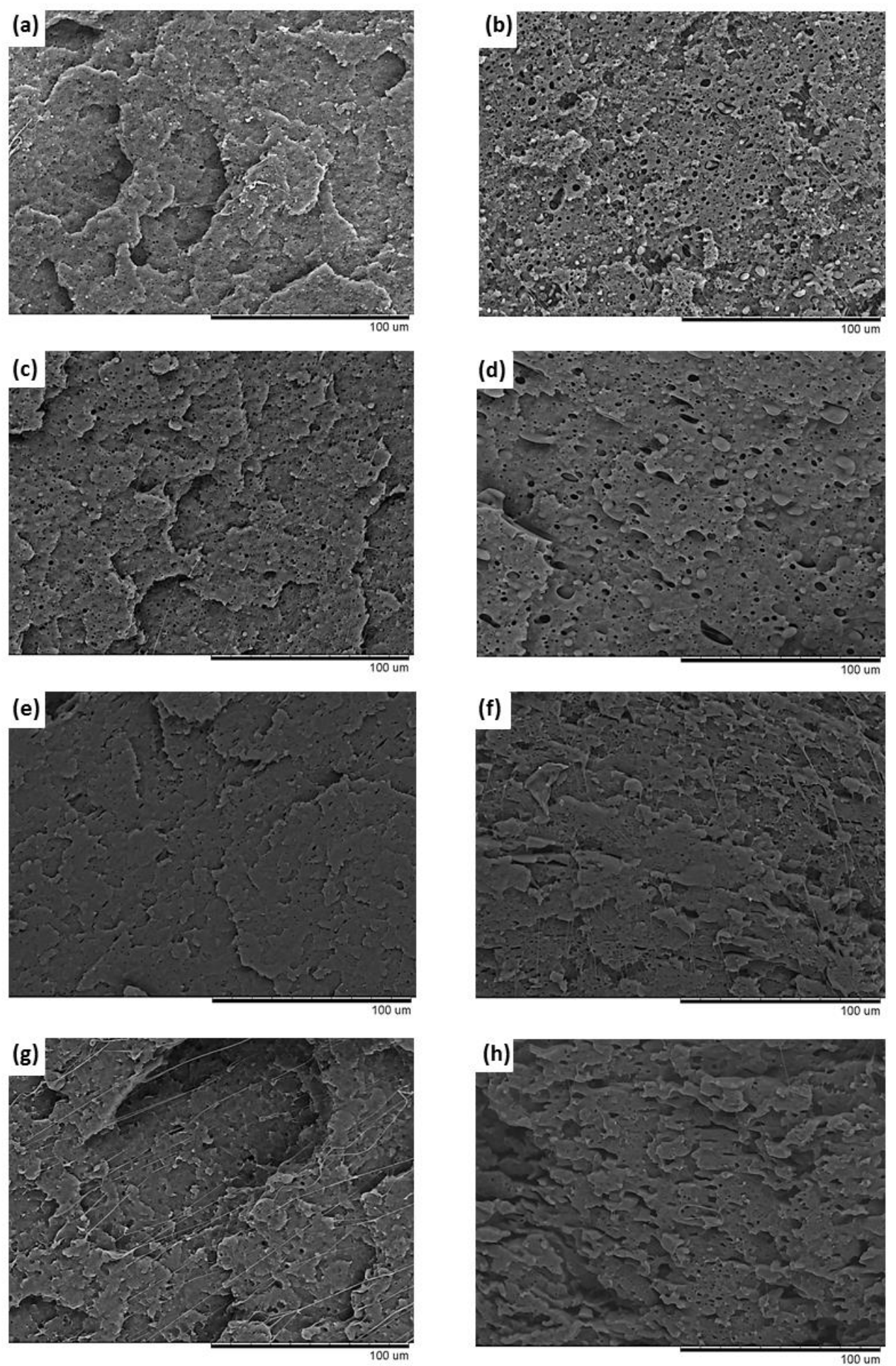

Figure S9. SEM images of the impact fractured surfaces of the blends. (a) 10\% DFA0 (b) 20\% DFA0 (c) $10 \%$ DFA0.3 (d) $20 \%$ DFA0.3 (e) 10\% DFA0.7 (f) 20\% DFA0.7 (g) 10\% DFA1 (h) $20 \%$ DFA 1. 

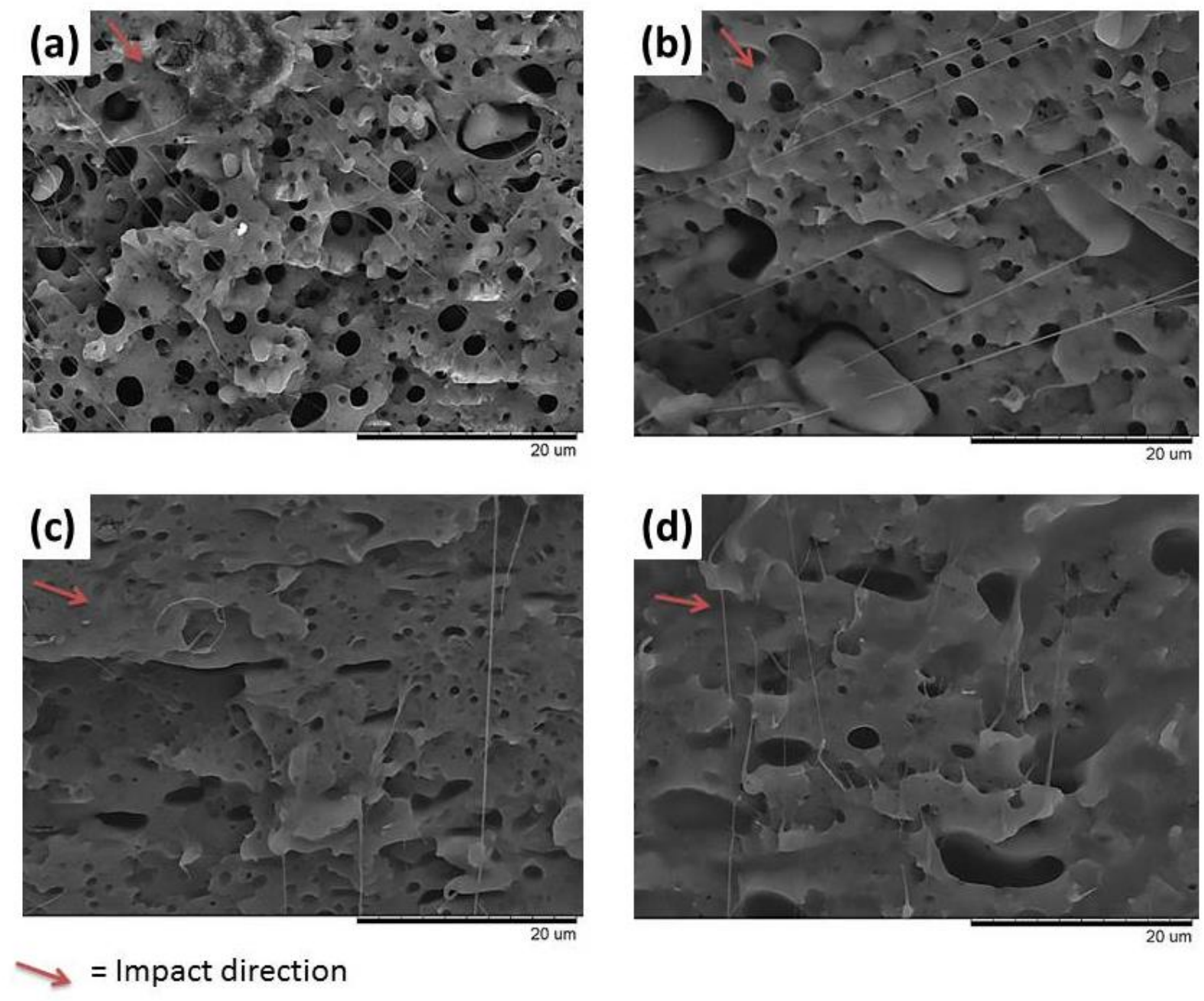

Figure S10. Zoomed-up SEM images of Figure 15. 